\title{
BANK SOVEREIGN BOND HOLDINGS, SOVEREIGN SHOCK SPILLOVERS, AND MORAL HAZARD DURING THE EUROPEAN CRISIS
}

\author{
Andrea Beltratti \\ René M. Stulz \\ Working Paper 21150 \\ http://www.nber.org/papers/w21150
NATIONAL BUREAU OF ECONOMIC RESEARCH
1050 Massachusetts Avenue
Cambridge, MA 02138

May 2015

We are grateful to Brian Baugh and Andrei Gonçalves for scientific assistance. We thank seminar participants at the European Central Bank and at the University of Lugano, Carlo Favero, Nicola Gennaioli, and Luigi Guiso for helpful comments. The views expressed herein are those of the authors and do not necessarily reflect the views of the National Bureau of Economic Research.

At least one co-author has disclosed a financial relationship of potential relevance for this research. Further information is available online at http://www.nber.org/papers/w21150.ack

NBER working papers are circulated for discussion and comment purposes. They have not been peerreviewed or been subject to the review by the NBER Board of Directors that accompanies official NBER publications.

(C) 2015 by Andrea Beltratti and René M. Stulz. All rights reserved. Short sections of text, not to exceed two paragraphs, may be quoted without explicit permission provided that full credit, including @ notice, is given to the source. 
Bank sovereign bond holdings, sovereign shock spillovers, and moral hazard during the European crisis

Andrea Beltratti and René M. Stulz

NBER Working Paper No. 21150

May 2015

JEL No. F34,G12,G15,G21,H63

\begin{abstract}
From 2010 to 2012, the relation between bank stock returns from European Union (EU) countries and the returns on sovereign CDS of peripheral (GIIPS) countries is negative. We use days with tail sovereign CDS returns of peripheral countries to identify the effects of shocks to the cost of borrowing of these countries on EU banks from other countries. A CDS tail return affects banks with greater exposure to the country experiencing that return more, but it has an impact on banks regardless of exposure. Shocks to peripheral countries that are more pervasive impact the returns of banks from countries that experience no shock more than shocks to small individual peripheral countries. In general, the impact of tail returns is asymmetric in that banks suffer less from adverse shocks to peripheral countries than they gain from favourable shocks to such countries.
\end{abstract}

\author{
Andrea Beltratti \\ Department of Finance \\ Bocconi University \\ Via Roentgen 1 \\ 20100 Milan \\ Italy \\ and FEEM \\ andrea.beltratti@intesasanpaolo.com \\ René M. Stulz \\ The Ohio State University \\ Fisher College of Business \\ 806A Fisher Hall \\ Columbus, OH 43210-1144 \\ and NBER \\ stulz@cob.osu.edu
}


Throughout the acute phase of the European sovereign crisis, policymakers were very much concerned that shocks to the cost of borrowing of peripheral countries (the GIIPS countries, namely Greece, Ireland, Italy, Portugal, and Spain) could endanger other countries and the financial system of the European Union (EU) as a whole. There was little doubt for policymakers that, as put by Vitor Constâncio, the vice-president of the ECB at the time, "contagion phenomena play a crucial role in exacerbating the sovereign debt problems in the euro areas." He went on to say that "Several of the ECB's interventions have been motivated by the need to address contagion". Shocks to the cost of borrowing of the peripheral countries could affect the cost of borrowing of healthier countries directly, but they could also affect countries and the financial system through their impact on banks. A key potential transmission channel of the crisis through banks was the fact that banks in healthy countries held bonds from peripheral countries. In this paper, we provide new evidence on the transmission of shocks to the cost of borrowing of peripheral countries to banks in other EC countries using data on bank exposures to peripheral countries.

Much attention has been paid to the complicated relation between sovereign risk and European banks (e.g., Acharya, Drechsler, and Schnabl (2014)). On the one hand, adverse developments concerning the cost of debt of sovereigns affect banks directly, partly because they hold sovereign debt, partly because of the sovereign debt credit rating ceiling, and partly because they rely on sovereigns for support. In addition, a worsening of the creditworthiness of a sovereign has indirect adverse effects on banks as it leads to a deterioration in economic activity and an increase in the cost of funds. At the same time, however, a worsening of the creditworthiness of banks in a country also has an adverse impact on the creditworthiness of the country. This impact arises because of the expectation that the country's government will have to rescue banks. Ireland provides perhaps the most striking example of this dialectic as a highly-rated sovereign saw its creditworthiness decline sharply as it bailed out banks. The fact that a weakening of banks can have an adverse impact on the creditworthiness of a country complicates any analysis of transmission of the crisis as this relation makes it harder to assess whether shocks to creditworthiness of countries cause a weakening of banks or the other way around.

To identify the impact of shocks to the cost of borrowing of sovereigns (sovereign shocks) on banks, we use an event study approach. With this approach, we look at the impact on banks of large sovereign shocks

\footnotetext{
1 "Contagion and the European debt crisis," keynote lecture at the Bocconi University/Intesa Sanpaolo conference on "Bank Competitiveness in the Post-crisis World," Milan, October 2011.
} 
measured as events where the credit default swap (CDS) return for one or multiple peripheral sovereigns is at the tail of the distribution of the CDS returns of the respective sovereign or sovereigns. As is conventional, we measure returns on CDS by the return to the protection buyer, so that a positive return corresponds to a worsening of the credit in that it becomes more expensive to insure against the credit. In the absence of frictions, a positive return on a CDS corresponds to a drop in the value of the bonds issued by the referenced name. We identify large sovereign shocks as one-day CDS returns that are more than two standard deviations away from the mean in absolute value. Such tail peripheral CDS returns cannot be attributed to news about banks from other (peripheral or non-peripheral) countries and hence make it possible to evaluate the impact of sovereign shocks on these banks.

Transmission of sovereign shocks to banks in other countries than those suffering from the sovereign shock could take place through two distinct channels. First, a sovereign shock could affect banks adversely because such a shock makes the financial system more vulnerable and could affect the economy of the bank's country through the weakening of the financial system or through a decrease in the demand for the country's products from the country affected by the sovereign shock. Hence, with this transmission channel, a bank would be affected even if it is not directly exposed to the country that experiences a sovereign shock. We call this channel the systemic risk channel. Second, a sovereign shock could affect a foreign bank because it is exposed to the country that suffers the shock. We call this channel the exposure channel. A bank could be exposed to a foreign country for a variety of reasons. For instance, it could have operations in that country. However, much attention has been paid to the exposure of banks through sovereign bond holdings. One potential factor affecting these exposures is that holding sovereign bonds from peripheral countries enabled banks to hold bonds with high yields without having to use regulatory capital as the risk weights of these bonds were zero (Acharya and Steffen (2012), Korte and Steffen (2014)). A bank that holds sovereign bonds from the country suffering the shock would experience a loss as the value of the bonds drop. In this paper, we investigate these two transmission channels.

To obtain data on bank exposures, we use the data from the stress tests that were required of EU banks starting in 2010. These stress tests provide data on large EU banks' exposure to the sovereign debt of European countries for five separate dates during our sample period from April 2010 to November 2012. Stress test banks had a strong home bias in their holdings of European sovereign debt. However, these banks 
also had on average material holdings of sovereign bonds from peripheral countries. We would expect a sovereign shock to have a worse effect for banks that hold more bonds issued by that country, whether these banks are located in the country or not. Using the data from the stress tests, we find that this is the case. However, we also find that sovereign shocks have an adverse impact on EU banks even if their exposure to the countries affected by the shocks is trivial.

Using returns on sovereign CDS as our measure of changes in the creditworthiness of European countries, we find first that there is a significant relation between stock returns on EU banks and CDS returns of peripheral European countries. This relation holds whether we exclude banks from the country whose CDS return we are using or not. For instance, EU banks other than Greek banks had a significant negative relation between their stock returns and the returns on Greek CDS. We then examine whether the relation differs depending on the extent to which banks are exposed to a country. We find that banks with higher exposure to a peripheral country suffer more when the CDS of that country has a positive return. Using a CDS index for peripheral countries equal to the average of the CDS returns for these countries, we show that EU banks have worse returns when that index experiences a positive return, i.e., when buyers of protection gain.

Having verified that there is a relation between CDS returns and bank stock returns in our sample and that the relation differs for banks with more exposure to peripheral country bonds, we proceed to examine the relation between sovereign credit shocks and bank returns more directly. To assess the impact of sovereign shocks, we select days with extreme positive or negative sovereign CDS returns, i.e., tail returns. We focus on tail return days because such days make it possible to assess more precisely the transmission of unexpected sovereign shocks on banks in countries other than those where the sovereign shock is taking place. Our approach is similar to an event study where the event is a sharp change in the cost of borrowing of a sovereign. Such an approach has been used in the literature to study contagion of unexpected deterioration in the credit of corporations (see Jorion and Zhang (2007)). Effectively, our identifying assumption is that extreme sovereign shocks as measured by sovereign CDS returns are not caused by shocks to banks from countries that do not suffer extreme shocks on the same day, even though they might be caused by shocks to banks in the country that suffers an extreme return. For instance, if Spain and Italy experience an extreme CDS shock on a day, our identifying assumption is that this shock is not caused by a shock to banks in 
France and Germany. Though it is not conceptually impossible that a shock to banks in France and Germany could lead to an extreme return on the sovereign CDS of Italy, we are not aware of such a situation during our sample period. An alternative approach would be to consider the impact of changes in credit ratings, but such an approach can understate the impact of the deterioration of the creditworthiness of a country because that deterioration could be incorporated in the sovereign's cost of borrowing before the rating change is announced.

To identify whether the CDS return of a country on a given day is a tail return, we estimate the standard deviation of the CDS return over the previous 60 trading days. With a CDS, a positive tail return occurs when buying protection on a credit becomes more expensive. This corresponds to a situation where the value of the bonds on which protection is bought falls. A positive tail return is a CDS return greater than two standard deviations. A negative tail return is a CDS return lower than minus two standard deviations. Using this approach, we find 104 positive tail returns and 49 negative tail returns between April 2010 (the first date for which we have holdings of sovereign bonds) and February 2012 (the last date for which we have data on Greek CDS). Not surprisingly, these tail returns are large in absolute value (-6.7\% for negative tail returns and $6.9 \%$ for positive tail returns). We estimate abnormal returns of banks on days of tail returns. We define core countries on a given day to be those with CDS premiums below the median for EU countries for that day. We show that the abnormal returns of banks in core countries are significant on days of tail returns in peripheral countries. The absolute value of the abnormal returns increases nonlinearly with the number of peripheral countries that have a tail return on a given day. Further, the abnormal returns are higher in absolute value on days of negative tail returns.

Having estimated abnormal returns on positive and negative tail return days, we investigate whether these abnormal returns are consistent with the exposure transmission channel. Using the stress test data, we find that bank returns are related to CDS tail returns irrespective of a bank's exposure, so that bank returns are lower on days of positive CDS tail returns and higher on days of negative CDS tail returns. Consequently, the evidence supports the existence of the systemic risk transmission channel. In addition to this effect, we find strong evidence for the exposure channel since a bank's return is related to the CDS return through the bank's holdings of bonds from the country with the CDS shock. We estimate these effects 
on banks that are not in the country with the CDS shock to insure that the CDS shock is unlikely to be attributable to shocks to the banks we consider.

We find that the impact of CDS tail returns on a bank depends on the pervasiveness of the shock across peripheral countries (defined as the fraction of the population of the peripheral countries affected by the shock) and on the exposure of the bank to the countries having the extreme tail return. For banks with no exposure, CDS tail returns originating from individual small peripheral countries have largely symmetric effects, but as the shock becomes more pervasive across peripheral countries, the impact of the shock becomes highly asymmetric. Effectively, the gain to a bank from a negative CDS tail return for all peripheral countries is more than four times the loss from a positive tail return for all of these countries. For a given exposure, the asymmetry increases as the shock becomes more pervasive when the exposure is within the range of exposure for core countries. However, within that range, an increase in exposure increases the asymmetry for shocks to small countries and decreases it for more pervasive shocks.

Banks with exposure appear to have borne less of the effect of adverse shocks to peripheral countries than they gained from positive shocks to these countries regardless of the pervasiveness of shocks. Since we are analyzing the impact of shocks on bank equity, it is important to remember that equity is a call option, so that, at high levels of leverage, there is an inherent asymmetry in the impact of positive and negative shocks. Another possible factor contributing to such an asymmetry is that banks might receive government support for losses on peripheral bonds, so that they do not have to suffer from the whole impact of such losses. The role of potential government support would explain why the asymmetry increases with exposure for shocks to small countries but not for more pervasive shocks. As a shock becomes more pervasive, the aggregate losses to banks increase as they make losses on bonds from larger countries and the potential availability of government support to mitigate losses will likely be more limited, which increases the adverse impact of the shock and reduces the asymmetry.

We explore how the transmission of sovereign shocks is affected by a bank's leverage. When we look at portfolio returns, we find no evidence that over our sample period better capitalized banks in healthier countries were less affected by CDS returns of peripheral countries. Such a result may not be surprising as returns over the sample period are unlikely to do a good job in capturing sovereign crisis transmission to banks as many other factors affect them. When we investigate how leverage affects the cross-section of 
abnormal returns on days of tail returns, we find that leverage does not seem to have any impact on the systemic risk transmission channel. In contrast, banks with less leverage are affected less through the exposure channel on days of positive tail returns. The impact of negative tail returns seems unrelated to leverage. In summary, therefore, leverage appears to worsen the impact of the exposure channel for positive sovereign tail return events.

Following the credit crisis, there has been much concern about the systemic risk posed by short-term bank funding. We investigate whether banks that have more fragile funding are more affected by sovereign shocks. We find no evidence that funding fragility plays any role in the contagion we document. Importantly, however, the ECB took exceptional steps to provide liquidity to banks from the end of 2010. Therefore, it could be that fragility plays no role in our regressions because of these actions.

Our paper contributes to a growing literature on the impact of shocks to the cost of borrowing of sovereigns on banks. Among contributions to that literature, Bolton and Jeanne (2011) model exposure contagion through sovereign bond holdings. Angeloni and Wolff (2012) find that banks' market performance in July-October 2011 was impacted by Greek debt holdings and in October-December 2011 by Italian and Irish sovereign exposure. Constâncio (2012) shows that the CDS premiums of French banks were increasingly explained by sovereign CDS during 2011. Lahmann (2012) finds evidence in favour of increasing interdependence between sovereign CDS and the CDS of banks located in other countries. Alter and Schuler (2012) show that European government CDS premiums have been an important determinant of banks' CDS in the period 2007-2010. Acharya, Drechsler and Schnabl (2014) provide empirical evidence for the two-way feedback between sovereigns and banks. They find that the bank-sovereign CDS relationship is stronger for less well-capitalized banks, banks with more short-term debt and banks located in countries with higher credit risk. Acharya and Steffen (2015) use the correlation between government bond returns and banks' stock returns to estimate the exposure of various European banks to sovereign debt, and show that such exposure is consistent with the exposure disclosed through the stress tests. Barth et al. (2012) study the links between bank and sovereign risk globally. Gross and Kok (2013) explore feedback effects between sovereign CDS and bank CDS using a global VAR model and show that there was contagion from sovereign CDS to bank CDS during the height of the European sovereign crisis. Most recently, Fratzscher and Rieth 
(2015) provide evidence that from 2003 to 2013 shocks to sovereign risk affect bank risk and vice versa, but they conclude that sovereign shocks have a bigger impact than bank risk shocks.

The paper proceeds as follows. We present our data in Section 1. In Section 2, we show that bank returns are related to country CDS returns during the period 2010-2012. In Section 3, we introduce CDS tail events and show bank stock abnormal returns on CDS tail event days. In Section 4, we investigate the bond holding contagion channel and the determinants of bank stock abnormal returns on tail event days. We conclude in Section 5 .

\section{Section 1. Bank exposures to sovereigns}

We use banks for which we have exposure data available so that we can investigate the exposure transmission channel. Our exposure data is from the disclosures required as part of the stress tests of EU banks. In 2010, a stress test exercise was conducted by the Committee of the European Banking Supervisors. Subsequent stress tests of EU banks in our sample period were the responsibility of the European Bank Authority (EBA). The 2010 and 2011 exercises covered around 90 banks representing 65\% of the EU market in terms of total assets and at least $50 \%$ in each member state. Further data on holdings of sovereign bonds by around 60 banks were made available through the 2011 and 2012 Recapitalization Exercises. Sixty-one of the reporting banks were listed in stock markets across Europe at the time they participated in the stress tests. However, the Austrian bank Oestern Volksbanken is very rarely traded and is excluded from the sample. The sample changes over time as banks appear or disappear. ${ }^{2}$

The data include both the gross direct long exposure to central and local governments as well as the net direct positions (equal to the gross long positions of the banks in the trading and banking books offset by cash short positions in the trading book with matching maturities). We use the net exposures in the results we report. The results are similar if we use gross positions. We have five snapshots of holdings, dated March 2010, December 2010, September 2011, December 2011, and June 2012. The release dates for the first three snapshots are respectively July 23, 2010, July 15, 2011, and December 8, 2011. The December 2011 and

\footnotetext{
${ }^{2}$ Datastream stops reporting prices for Landesbank Berlin on July 31, 2012, ITT Hellenic on August 30, 2012, Agricultural Bank of Greece on July 26, 2012, Banco Guipuzcoano on November 12, 2010, Caja de Ahorros del Mediterraneo on December 8, 2011, Banco Pastor on February 27, 2012, Irish Life and Permanent on June 11, 2012. Bankia enters the sample on July 21, 2011.
} 
June 2012 data were jointly released on October 3, 2012. We only include the banks for which stock returns from Datastream are available.

When assessing the exposure of a bank with respect to a specific peripheral country, we can assume that a bank has the exposure from the date of the balance sheet that is reported with the stress test or we can assume that it has this exposure only from the date that the stress test results are made public. We call the first approach the balance sheet date approach and the second the disclosure date approach. With the disclosure approach, we use exposures reported on the first stress test disclosure on July 26, 2010, and then change the exposures sequentially on the first trading day after each one of the subsequent stress test disclosures. With the balance sheet approach, we use exposures reported with the first stress test starting on April 1, 2010 since the exposures correspond to bank balance sheets for the end of March. We then change the exposures sequentially on the balance sheet date that correspond to stress test disclosures. Most of the results we report use the balance sheet approach. The benefit from doing so is that it allows our sample to start on April 1, 2010, instead of July 26, 2010. However, we find that our results hold irrespective of the approach we use and report results using both approaches for our most critical results.

In Table 1, we show summary measures of exposures using the data for March 2010 in Panel A and the data for September 2011 in Panel B. The reason why we use September 2011 and not June 2012 for the comparison is that the third stress test was the last one with disclosure of sovereign holdings of Greek banks. We normalize exposure by tangible equity which is computed using data from Worldscope. Tangible equity is defined as equity minus intangible assets. We show the information for banks from each peripheral country as well as for banks from core countries. We define a core country to be any country with a CDS premium below the median level of CDS premiums of the EU countries. ${ }^{3}$ Only one panel has information about derivatives because that information was not disclosed in the first stress test.

The table shows that banks from peripheral countries have large exposures to bonds from their own country. However, these banks also have exposures to other peripheral countries. These exposures are especially large for Portuguese banks. The banks from the core countries have on average exposure to peripheral countries amounting to $33.03 \%$ of their tangible equity for the 2010 data. With the 2012 data, the banks in the peripheral countries have more exposures to their own country than in 2011, but the banks from

\footnotetext{
${ }^{3}$ The core countries at the start of the sample are Belgium, Denmark, Finland, France, Germany, The Netherlands, Norway, Slovenia and Sweden.
} 
the core countries have less exposure to the peripheral countries as the average exposure has fallen to $17.03 \%$. Panel B shows that in most cases the derivatives exposure is trivial. Surprisingly, the only cases where derivatives positions represent more than $1 \%$ of tangible equity are cases where derivatives are used to increase exposure rather than to hedge.

Other data, not included in the table, are helpful to obtain a better understanding of sovereign bond holdings for our sample. If we order EU banks by holdings of Greek sovereign bonds in 2009, we find the top six places are assigned to Greek banks. The largest holder was National Bank of Greece with net holdings amounting to almost 20 billion euros, while the largest holder in terms of tangible equity was Agricultural Bank of Greece with an exposure equal to $763 \%$ of its tangible equity. The Greek bank Alpha had the lowest exposure of the six top holders, amounting to $87 \%$ of its tangible equity capital. In terms of tangible equity, the largest non-Greek and non-Cypriot holder of Greek bonds was Deutsche Postbank with an exposure of $46 \%$ of its tangible equity. Thirteen banks, many of them from Northern Europe, had no net exposure in Greek bonds. The thirty-third percentile of the empirical distribution was $0.43 \%$ and the sixtysixth $4.6 \%$; the median was equal to $1.95 \%$, and the mean $44.52 \%$. In the case of Irish bonds, Allied Irish Bank had an exposure of $39 \%$ of tangible equity capital and Bank of Ireland of $20 \%$. For Irish bonds, therefore, there was a home bias but the exposure of domestic banks to domestic bonds was much lower than the one of Greek banks. For Italian bonds, the five major Italian banks are among the top nine holders, with Monte dei Paschi di Siena being exposed for $283 \%$ of tangible equity, Intesa Sanpaolo for $227 \%$, and Unicredit for $105 \%$. However, the third largest holder was Dexia with a gross exposure of $179 \%$ of tangible equity. Dexia was also the largest non-Portuguese holder of Portuguese bonds (gross exposure equal to 29\% of tangible equity). Another seven banks, six of which are from Portugal or Spain, had more than 5\% of their tangible equity invested in Portuguese sovereign bonds; however none, apart from Banco BPI with an exposure of $184 \%$ of its tangible equity, had an exposure larger than $15 \%$. The largest holders of Spanish bonds were Spanish banks, with an average exposure equal to $132 \%$ of tangible equity, whereas non-Spanish banks had an average net exposure of $4.17 \%$.

The detailed data shows that exposures varied widely across banks. While many banks had exposures low enough that losses on sovereign bonds from peripheral countries were unlikely to have much of an impact on them, other banks had holdings large enough that losses on sovereign bonds could potentially 
cripple them or even make them insolvent. In general, the largest exposures are by banks from peripheral countries to the bonds of their countries. The home bias was therefore always present, but with different magnitudes, with a large bias for Greek, Italian and Spanish banks and a much lower exposure for Irish and Portuguese banks.

\section{Section 2. Sovereign risks and bank returns}

In this section, we investigate the relation between bank stock returns and changes in the cost of debt of the peripheral countries. To estimate a sovereign's cost of debt, we use its CDS premium from Markit for the five-year maturity CDS contract. The CDS premium is the annual premium that has to be paid by the protection buyer to receive protection against a default of the underlying name. This data is widely used by practitioners and academics. Note, however, that Markit has no CDS data for Greece after February 28, 2012. The CDS return is the return on a CDS position for a protection buyer, computed as the percentage change of the premium. Hence, a positive CDS return corresponds to a worsening of the creditworthiness of a country's sovereign.

It is useful to note that compared to most CDS the CDS of the peripheral countries were highly traded. A recent study of CDS non-dealer volume from July 2010 to the end of 2014 shows that the only CDS name that was more actively traded than the CDS of Italy and Spain was Brazil. ${ }^{4}$ The least traded CDS name among the peripheral countries is Ireland, which is the $71^{\text {st }}$ most traded CDS name over that period.

Table 2 shows the equally-weighted bank stock returns and CDS returns for the countries in our sample. Our sample period is from April 2010 to November 2012 for all the results that do not use Greek CDS data. We stop our sample in November 2012, which is the month when the restrictions on short selling and naked credit default swap positions came into effect in Europe. By the end of our sample period, the most acute part of the crisis was over. ${ }^{5}$ For the results that use Greek CDS data, our sample period stops at the end of February 2012 because there is no data after that date. Not surprisingly, there is considerable variation across countries in both bank returns and in CDS returns. During our sample period, the average CDS return across sample countries is positive at $0.17 \%$. The peripheral countries have much higher average CDS returns than

\footnotetext{
${ }^{4}$ See Donald R. van Deventer's Blog, Sovereign credit default swaps and the European commission short sale ban, 2010-2014, Kamakura Corporation.

${ }^{5}$ See http://www.esma.europa.eu/page/Short-selling.
} 
the country average for the sample except for Ireland. The reason that the average CDS return of Ireland is lower than the average is that the CDS premium of Ireland fell sharply after increasing dramatically early in the sample period. The highest CDS return is for the Greek CDS and is $1.06 \%$. The country with the second largest CDS return among the peripheral countries is Portugal. Spain and Italy have similar average CDS returns. The average CDS returns for Portugal, Spain, and Italy are, respectively, $0.37 \%, 0.26 \%$, and $0.25 \%$. The last column of the table shows how frequently a country is included among the core countries.

To assess the relation between CDS returns and bank returns, we first estimate in Table 3 a regression of the return of an equally-weighted portfolio of banks in core countries on an index of stock returns of nonfinancial firms (an equally-weighted portfolio of sectors different from financials in the Euro Stoxx) and an equally-weighted index of CDS returns of peripheral countries. On a given day, the country is defined as a core country if its CDS premium for a five-year contract is below the median CDS premium across countries in the sample. We do the same for non-core countries, which are all the other countries. For the regression using banks from core countries, the CDS index has a negative coefficient of -0.118 and it is significant at the $1 \%$ level. With this estimate, a $1 \%$ return on the CDS index would translate in a decrease in the return of the bank index of $0.118 \%$. When we estimate the same relation for non-core countries, the coefficient on the CDS index is -0.197 , which is almost twice the size of the coefficient of the index for banks from core countries and is significantly different from that coefficient. The non-core countries are also significantly less exposed to the index of non-financial firms.

To understand whether the exposures of core country banks to the index differ depending on the leverage of banks, we form portfolios that are long banks with tangible equity to assets in the top tertile of banks in the core countries and short banks in the bottom tertile. We obtain tangible equity for the banks in our sample from Bankscope. The estimated regression shows that highly levered banks located in core countries are riskier, in that they have more exposure to the benchmark, but they are not more exposed to the CDS index return. When we turn to the estimated regression for non-core banks, we find that the highly levered banks are less exposed to the benchmark and more exposed to the CDS index return (at 10\% significance). However, there is no significant difference in the exposure to the CDS index return of the high minus low leverage portfolios between core and non-core countries. The differential exposure to the CDS index of banks with lower leverage is economically small. In non-core countries, an increase in the CDS index equal 
to $5 \%$ is associated with a rate of return differential in favour of more capitalized banks equal to 14 basis points.

Having established that our sample bank returns are related to CDS returns, we now turn to the relation between bank returns and CDS returns for individual peripheral countries. The results are in Table 4. For each peripheral country, we show estimates of our regression for the banks from that peripheral country, for the non-core banks (excluding banks from that peripheral country), and for core banks. The first three columns show the results for Greece. We see that all three sets of banks have returns related to the CDS return of Greece. However, the coefficient is five times larger in absolute value for the Greek banks than it is for the other banks. In the regressions for each other peripheral country, the coefficient on the sovereign CDS return is significantly negative. In all the regressions, the coefficient on the CDS return is substantially larger in absolute value than for Greece. For each peripheral country, the coefficients are significantly different in absolute value for banks from core countries in comparison to non-core banks except for Greece.

To examine the role of exposures more directly, we build portfolios of core and non-core banks that are long the banks most exposed to a peripheral country and short the banks least exposed to the same country. To form high (low) exposure portfolios for day $t$, we rank banks on the basis of the ratio of net bond holdings to tangible equity and consider the equally-weighted portfolio of banks whose exposure is lower (larger) than the $33^{\text {rd }}\left(66^{\text {th }}\right)$ percentile of the common distribution across all banks for that day. Figure 1 shows the cumulative returns of the portfolios of core-country banks with high and low exposure. It shows that by the end of the sample period the portfolio of banks with high exposures had fallen by almost $40 \%$ while the portfolio of banks with low exposure had increased by $20 \%$.

Table 5 presents estimates of regressions of core and non-core long-short exposure portfolios. Panel A shows results using the balance sheet date approach. Results with the disclosure date approach are shown in Panel B. We regress portfolio returns on the benchmark and the CDS return. Considering Panel A first, we find that every long-short portfolio for core country banks has a negative coefficient on the CDS return except for Greece, so that the value of the portfolio falls when the cost of borrowing of the peripheral country increases. We would expect such a coefficient if banks with more exposure suffer more from a deterioration of the credit of the country. These regressions are therefore consistent with exposure to a country increasing the sensitivity of banks to the creditworthiness of that country. We estimate the same 
regressions for non-core banks (excluding the peripheral country for which exposure is computed) and find similar results, except that with non-core banks the coefficient for Greece is significant but the coefficient for Spain is not. Turning to Panel B, the results are similar except that the coefficients are larger in absolute value for the core country portfolios but not for the non-core country portfolios.

It is noteworthy that the long-short portfolios have a significant positive coefficient on the benchmark portfolio. In other words, the long-short portfolios have a positive beta on the market portfolio (net of financials). To the extent that the beta of a portfolio is a measure of its risk, this means that banks that have higher exposures to peripheral countries are also riskier banks in their exposure to the market.

\section{Section 3. Sovereign tail risk events and bank returns}

In Section 2, we showed that bank returns are related to CDS returns of peripheral countries. This is true both for banks from core countries and those from non-core countries. While the regressions we have shown are instructive, they do not provide direct evidence that high CDS returns of peripheral countries cause poor bank returns and whether such shocks have a broader effect in that they cause poor returns to banks that are not exposed to these countries through bond holdings. In this section and the next, we examine causation more directly by investigating the impact of large unexpected CDS sovereign shocks. Large unexpected sovereign one-day CDS shocks can be viewed as exogenous for banks from countries without a simultaneous CDS shocks. To obtain further reassurance that we should not be concerned that shocks are due to banks in countries without shocks, we examined headlines in the Financial Times for our whole sample period. In no case did we find an instance where the CDS shock of a country occurs because on the same day there is a shock to a bank outside that country. We use an event-study design, so that we examine the abnormal returns of banks on days of large sovereign shocks. We compute abnormal returns as returns that are not explained by the benchmark index that we used in the regressions of the previous section. Since the markets for sovereign CDS as well as the markets for bank stocks for our sample are fairly liquid, we estimate the sameday impact. In the language of event studies, we use one day as our event window.

To obtain our sample of sovereign shocks, we select dates when the CDS premium in each of the peripheral countries jumps by an amount that is larger (smaller) than twice the rolling CDS return standard deviation measured over the previous sixty trading days. We call CDS returns on days of sovereign shocks 
tail returns. By construction, such tail returns are low probability events. Table 6 shows the distribution of tail returns across countries from April 2010 to February 2012. Our sample period ends in February 2012 as there are no Greek CDS quotes after that month. In the sample, there are many more positive tail return events, 104, than there are negative tail return events, 49. A day with at least one tail return is much more likely to have multiple tail returns than just one. We see that our sample has 15 days where only one country has an extreme negative return and 32 days where only one country has an extreme positive return. The fact that it occurs frequently that one country has a tail return in a day where more than one country has a tail return complicates our analysis in that the relevant exposures when there is a tail return are the exposures to all countries that have a tail return that day.

Table 7 shows CDS returns and bank stock abnormal returns for the days that the peripheral countries have negative and positive tail returns. We distinguish between days where there is at least one tail return in panel A and days where there is only one tail return in panel B. For CDS, the estimates are obtained from a regression of all tail return days of the peripheral country considered on a constant and indicator variables for positive and negative tail return days of the country considered. For stocks, we estimate the same regression but add the benchmark index return. Turning first to panel A, we see that the average CDS returns on tail return days are extremely large in absolute value, but quite similar in absolute value between positive tail returns and negative tail returns. For instance, for Italy, the average positive tail return for CDS is $12.16 \%$ and the average negative tail return is $-13.23 \%$. There is no country for which there is a significant difference for the absolute value of the CDS returns between positive and negative tail return days. On days when a peripheral country has a tail return, the returns of CDS from core countries are quite high in absolute value as well. Keeping with the example of Italy, the return of core countries is $5.73 \%$ for a positive tail return day and $-6.55 \%$ for a negative tail return day. Perhaps surprisingly, the non-core countries CDS returns on days that peripheral countries have tail returns are only slightly larger in absolute value than the CDS returns of core countries on the same days, namely $5.93 \%$ for a positive tail return day and $-7.05 \%$ for a negative tail return. When we turn to Panel B, where we restrict the sample to days where only one peripheral country has a tail return, we find that the CDS returns of the countries having tail returns are similar to those of Panel A. However, the CDS returns of core countries are much smaller except for Italy and Spain. The same 
conclusion holds for non-core countries. Note that there is only one day for which Italy has a negative tail return only by itself.

We now consider the abnormal returns on days that peripheral countries have CDS tail returns. In panel A, the equally-weighted portfolio of the stress test banks from core countries has a significant negative abnormal return when a peripheral country has a positive tail return and a significant positive abnormal return when the same country has a negative tail return irrespective of the country. There is a strong asymmetry in the abnormal returns when Italy, Portugal, and Spain have tail returns, but not for the other countries. For instance, the bank portfolio from core countries has a negative abnormal return of $-0.51 \%$ when Italy has a positive tail return and of $1.44 \%$ when Italy has a negative tail return. The two returns differ in absolute value at the $10 \%$ level. The results for the banks in non-core countries (which exclude the peripheral countries having tail returns) are similar to the results for banks in core countries, except that the asymmetry is no longer significant when Portugal and Spain have tail returns. Lastly, we show returns for banks located in the peripheral country with a tail return. Not surprisingly, these abnormal returns are often, but not always, the largest in absolute value. Panel B looks at the same abnormal returns for the sample restricted to the days when only one peripheral country has a CDS tail return. Almost none of the bank abnormal returns are significant and there is no evidence of asymmetry. When we turn to banks in core countries, we see that the abnormal returns are significant for Italy and when Spain has a positive tail return. In the case of Italy, there is significant asymmetry.

We also construct exposure long-short portfolios for banks in core countries and for banks in non-core countries. The portfolios are constructed by taking a long position in the banks that are in the top tertile of exposure and short in the banks that are in the bottom tertile of exposure. There is little evidence of significant abnormal returns in Panel A. Strikingly, however, the evidence exists only for negative tail return days, since Ireland, Italy, and Portugal have significant abnormal returns on negative tail return days. Turning to the banks in non-core countries, the abnormal returns for tail returns days are significant both for Italy and for Spain, but not for other countries. Turning to Panel B, the abnormal returns for Italy are significant, but the abnormal returns for other countries are not.

In Table 7, the results are much stronger when multiple countries have tail returns. To explore further the relation between bank returns on tail return days and the number of countries with tail returns, we estimate 
regressions of portfolio abnormal returns on tail event days on a constant and a variable equal to the number of peripheral countries that have tail returns for each tail return day and report the results in Table 8 . The first three regressions use portfolios of all banks. We see with Model 1 that the average return increases with the number of countries with negative tail returns and falls with the number of countries with positive tail returns. There is a strong asymmetry in that the coefficient on negative tail returns is twice the size in absolute value of the coefficient on positive tail returns. We add squared terms for the number of tail returns in Model 2. We see that the squared term on the number of negative tail returns is positive and significant. Hence, the excess return increases more than proportionately when the number of negative tail returns increases. The other coefficients are not significant and there is no evidence of asymmetry, but there are concerns about multicollinearity when we have both linear and quadratic terms. Finally, we have only the squared terms in Model 3. Both coefficients are significant and there is strong evidence of asymmetry. The next three models provide estimates for excess returns of core countries. The results are essentially the same as for the whole sample, except that we find strong evidence of asymmetry when we have the linear and quadratic terms as well. Turning to the non-core countries, we find results that are similar to those for the sample as a whole. The last three models are estimated for the countries experiencing tail returns. The evidence is weaker for these models. For them, there is no evidence of asymmetry and the coefficients are all significant only with the model that has only squared terms.

It follows from Tables 7 and 8 that there is much stronger evidence of transmission of sovereign shocks when multiple peripheral countries have CDS tail returns and that the impact of sovereign shocks on banks from countries that are not subject to a sovereign shock is strongly asymmetric on the days that multiple countries have CDS tail returns.

\section{Section 4. Sovereign tail risk events and the cross-section of bank returns}

In this section, we test for the systemic risk transmission channel and the exposure transmission channel using the cross-section of abnormal returns. Systemic risk transmission occurs irrespective of exposure. Hence, if this was the only transmission channel, exposure should be irrelevant in explaining the abnormal returns, but we should see negative abnormal returns for banks on days of tail returns. Alternatively, if only the exposure transmission channel is relevant, the abnormal returns should be zero if exposure is zero. 
To test for the systemic risk and the exposure transmission channels, we follow the approach used in finance to explain abnormal returns in event studies. We regress bank abnormal returns on CDS tail return days on indicator variables for the sign of the tail return, on CDS returns, and on bank characteristics. For each regression we estimate, the sample is composed of the stress test banks for which we have abnormal returns that are not banks in the peripheral country or countries with a CDS tail return on that day.

Summary statistics for the bank characteristics and the CDS returns on CDS tail return days are given in Table 9. As before, our proxy for leverage is Tangible equity, which is the ratio of tangible equity to total assets. The sample mean is $4.62 \%$. There is a large range for this variable and the standard deviation is $2.25 \%$. We show tangible equity for core and non-core countries. Tangible equity is higher for banks from non-core countries than for banks from core countries. Our second bank characteristic is Fragility, which is a measure of the risk to the bank from its funding and comes from Demirgüç-Kunt and Huizinga (2010). The measure is defined as one minus the ratio between customer deposits and total deposits plus short-term funding. This measure decreases as a bank's funding other than long-term debt and equity is composed of more deposits from customers. The sample mean is $28.88 \%$ and the standard deviation is $13.26 \%$. We show next summary statistics for our exposure measures.

The mean value of the $\log$ of assets is 5.073 corresponding to an average value of assets equal to about 160 billion euros. Total assets of the smallest and largest banks in the sample are respectively equal to 3 billion euros and more than 2 trillion euros. Banks from core countries have log total assets that average 5.838 corresponding to an average size of 343 billion euros; the corresponding average for banks located in non-core countries is only 90 billion euros. The difference is statistically significant. Overall, banks from non-core countries are smaller, have less leverage and less financial fragility.

The last bank characteristics we report in Table 9 are summary statistics for exposure to peripherals over assets for all banks, for core country banks, and for non-core country banks. We see that the mean is $4.06 \%$, but there is considerable variation across banks, especially between banks in core countries and banks in non-core countries. The mean for banks in core countries is only $0.45 \%$ in contrast to a mean of $7.20 \%$ for banks in non-core countries. The maximum exposure is 3.35\% for banks in core countries and $34.04 \%$ for banks in non-core countries. Note, however, that non-core countries include peripheral countries, so that for 
a subset of non-core countries, holdings of peripheral country sovereign bonds include holdings from their home country.

We now turn to the summary statistics for the CDS returns. The mean peripheral positive CDS return on a tail return day is $6.86 \%$ with a standard deviation of $6.61 \%$. The mean core positive CDS return on a day when at least one peripheral country has a positive tail return day is only $3.75 \%$ with a standard deviation of $4.10 \%$. CDS returns of core countries go up less, and are less volatile, than CDS returns of peripheral countries whenever at least one peripheral country has a positive tail return. When there is a negative tail return, peripheral country CDS have a return of $-6.70 \%$ and the average CDS return is $-3.04 \%$.

Using these variables, we estimate regressions that are shown in Table 10. The table has five panels. We cluster the standard errors by country. In Panel A, we use any day on which there is at least one CDS tail return for a peripheral country. On a day with multiple tail returns, we average equally across the countries having tail returns. In Panel B, we repeat the analysis of Panel A but we add a variable which proxies for the importance of the countries affected by a tail return and interactions with that variable. This variable, called country size, is the ratio of the population of the affected countries to the population of the peripheral countries. When we interact country size with other variables, we demean country size in the interaction using the mean of country size for the shocks for which the interaction is computed. This approach is a reasonable way to assess the role of the importance of the shock on bank stock returns. We would expect that negative tail returns for countries like Italy and Spain should have more of an adverse impact on the financial system than negative tail returns from Greece, Ireland and Portugal. We also would expect a shock that affects more peripheral countries to have more impact. In Panel C, we use disclosure dates to construct our sample and repeat the analysis of Panel B. In Panel D, we only use the days where there is one and only one CDS tail return for a peripheral country and repeat the analysis of Panel A. Finally, in Panel E we use only banks from the Eurozone and repeat the analysis of Panel A. While the stress tests were required of banks in the EC, countries that were not in the Eurozone did not participate in the European Financial Stability Fund which was created in June 2010 that provided assistance to Ireland, Portugal, and Greece. By estimating our regressions only on Eurozone banks, we can assess whether sovereign shocks transmission differed for these banks. 
In Model 1, we regress the abnormal returns on indicator variables for, respectively, positive tail return days and negative tail return days. For systemic risk transmission to exist from adverse shocks, it has to be that the coefficient of the indicator variable for positive CDS tail return days is negative. A necessary condition for what Mario Draghi, the President of the ECB, has called positive contagion to exist, is that the indicator variable for negative CDS tail return days has to be positive. ${ }^{6}$ We find that the abnormal return is significantly negative on positive tail return days and significantly positive on negative tail return days. We find evidence of asymmetry at the $10 \%$ level.

In Model 2, we add to Model 1 the interaction of the CDS return with the indicator variables for positive and negative tail CDS return days. We would expect higher CDS absolute returns on tail return days to have more impact through the systemic risk channel. When multiple countries have tail returns, we average the CDS returns across the countries that have tail returns. Note that in this regression we expect the coefficient on a negative tail return to be negative so that the total effect of a negative tail return is positive on bank returns. We find that both interactions have significantly negative coefficients. The asymmetry for the indicator variables for positive and negative tail return days is not significant in this regression.

Our evidence so far shows that sovereign shocks are transmitted to banks from countries where the shock is not taking place. It cannot distinguish between the systemic risk channel of transmission and the exposure channel of transmission because both channels predict the coefficients we find. We now take into account exposure measures. We measure exposure with the ratio of net holdings of bonds divided by total assets. Model 3 shows that bank returns are negatively related to exposure on positive tail return days and positively related to exposure on negative tail return days. The absolute value of the coefficient is much larger for negative tail return days than for positive tail return days. This asymmetry is large as the coefficient is almost twice as large in absolute value for negative tail return days. One way to see the economic implication is to consider the case where the exposure is $5 \%$ instead of $0 \%$. In this case, for a positive tail return day, the bank has a negative return of $0.40 \%$ if it has no exposure and a negative return of $1.70 \%$ if it has a $5 \%$ exposure. Consider now a negative tail return day. In this case, the bank gains $0.56 \%$ if it has no exposure and $2.65 \%$ if it has a $5 \%$ exposure. The coefficients on the exposure variables interacted with the indicator variables for

\footnotetext{
${ }^{6}$ See "Draghi Hails 'Positive Contagion' as Euro Markets Stabilize," by Jeff Black, Bloomberg, January 10, 2013. Note that a positive coefficient would be consistent with positive contagion, but the sign of the coefficient is not a test of whether there was such contagion.
} 
the sign of the tail return are consistent with a role for the exposure channel. However, the coefficients on the indicator variables are still significant. It follows that tail returns affect bank returns even if they do not have exposures. Consequently, our results support the existence of both a systemic risk channel and an exposure channel of transmission of sovereign shocks.

In Model 4, we use all the variables that we use in Models 2 and 3. Adding the CDS tail return to Model 3 does not affect the conclusion that exposure has a strong asymmetric effect on bank returns. Next, we add to Model 4 an interaction between exposure and the tail return. With interactions of continuous variables, we demean the interacted variables to facilitate the interpretation of the coefficients. With this model, we have two sets of variables with exposure and two sets of variables with the CDS return, which creates difficulties with multicollinearity. Nevertheless, we see that the coefficients on exposure interacted with the CDS return are strongly asymmetric in that the interacted coefficient on negative tail return has a larger absolute value than the other coefficient, but only the coefficient on negative tail return days is significant. The latter coefficient is negative as expected. Adding these variables has little impact on the coefficients on the exposure variables.

The results so far show that in general exposure has the predictable effect on bank returns and that there is a strong asymmetry in the coefficients on exposure. The asymmetry is that banks benefit more from a decrease in CDS premiums than they are hurt from an increase. Another way to put this is that they are hurt less by a worsening of the sovereign credit of peripheral countries than they benefit from an improvement in the sovereign credit of peripheral countries. For a levered firm, a 1\% increase in the value of assets has a larger impact on the value of equity than a $1 \%$ decrease in the value of assets because the value of equity is a convex function of the value of the assets. We examine next whether a bank's equity ratio affects the impact of tail returns on its bond holdings.

We would expect that equity should be affected proportionately less if leverage is lower and this effect to be asymmetric. We would also expect the bank's equity cushion to reduce the impact of tail returns though the systemic risk channel. To investigate these predictions, we add the ratio of tangible equity to assets as a variable and then interact that ratio with exposure in Model 6. If a greater equity cushion decreases transmission through the systemic risk channel, we would expect the coefficient on tangible equity interacted with the indicator variable for negative tail returns to be positive. There is no evidence from our regressions 
that less leverage mitigates transmission through the systemic risk channel. The coefficient on equity is not significant for positive tail return days or negative tail returns days.

If transmission through the exposure channel is mitigated by a greater equity cushion, we would expect the coefficient on the interaction to be positive as well. The coefficient on equity interacted with exposure on positive tail return days is positive and significant. The coefficient on equity interacted with exposure on negative tail return days is not significant. The impact of leverage on the transmission of adverse shocks through the exposure channel is economically large compared to the magnitude of the unconditional impact of adverse shocks. To see this, note that with Model 1, a positive tail return day is associated with an abnormal return of $-0.455 \%$. Consider now a day where half of the peripheral holdings are affected by a sovereign shock, which corresponds to $2 \%$ of the assets using the averages of Table 9 . A bank with tangible equity of $5.652 \%$ of assets, or 100 basis points above the mean of the sample, loses nothing on that day. In contrast, a bank with tangible equity of $1 \%$ of assets loses $0.99 \%$, or more than twice what it would lose without exposure.

Finally, in Model 7, we explore whether the fragility of a bank's balance sheet plays a role in the reaction of its stock price to CDS tail returns. The estimates of Model 7 show that no variable using fragility is significant. Funding of banks is therefore not a determinant of the transmission of the sovereign shocks we investigate.

We now turn to Panel B where we use the country size variable. Model 1 of Panel B is the same as Model 1 of Panel A. In Model 2, we add the country size variable interacted with indicator variables for the sign of the tail return. We see that positive tail return days have a significantly worse impact when the shock is more pervasive. Country size has no significant effect on bank returns for negative tail days. Model 3 repeats Model 3 of Panel A to facilitate comparison. Model 4 estimates the same regression with the country size variable interacted with indicator variables for the sign of the tail return. We see that country size has a significant impact for both positive tail days and negative tail days. This effect is asymmetric as it is larger in absolute value for negative tail return days. However, the asymmetry associated with exposure is no longer significant. When we also interact exposure with country size in Model 5, we see that exposure is now again asymmetric and that the interaction of exposure and country size reduces the asymmetry in that the impact of exposure worsens for positive tail return days when the shock is more pervasive. As a result, the asymmetry 
of the exposure effect decreases when the shock becomes more pervasive. Using Model 5, we find that a bank with exposure of $0.5 \%(4 \%)$ experiences a return of $-0.36 \%(-0.58 \%)$ for a positive tail CDS return in one of the smallest countries (proxied by country size set to 0.1$)$ and of $-0.89 \%(-3.00 \%)$ for a positive tail CDS return in all peripheral countries. In contrast, the bank has a positive return of $0.33 \%(1.30 \%)$ for a negative tail return in one of the smallest countries and a return of $2.62 \%(4.05 \%)$ for a negative tail return in all peripheral countries. More generally, given exposure, the impact of a shock is an increasing function of country size. Further, given country size, the impact of a shock increases with exposure. Finally, the asymmetry increases with exposure when country size is less than approximately 0.5 and decreases when country size is higher than approximately 0.5 . For low country size and low exposure, there is no asymmetry. The highest asymmetry occurs for country size of 1 with no exposure. In Models 6 and 7, the variables using equity and fragility are never significant.

The results in Panels C, D, and E are largely consistent with the results of Panels A and B. In Panel C, the results are similar to those of Panel B, except that the interaction of country size and exposure is symmetric. In contrast, there is evidence that the exposure effect is asymmetric in Panels D and E. In general, the results of Panel D are somewhat weaker, which is perhaps not surprising as they exclude days where multiple countries have tail returns.

\section{Section 5. Conclusion}

In this paper, we investigate the impact on EU banks of shocks to the cost of borrowing of peripheral countries. We consider two channels of transmission of sovereign shocks. The first channel is the impact of the shock to the financial system, which is an impact independent of the exposure of a bank to the country affected by the shock. We call this channel the systemic risk channel. The second channel is the impact of the shock on bonds from the sovereign affected by the shock held by a bank. We call this channel the exposure channel. Using banks that had to report results of stress tests between 2010 and 2012, we provide evidence that sovereign shocks impacted banks through both channels. We find strong evidence of asymmetry in the impact of shocks. Specifically, shocks that decrease the value of bonds from peripheral countries have a smaller absolute impact on banks than shocks that increase the value of bonds from these countries. Another way to state these results is that banks are hurt less by adverse shocks to peripheral 
countries than they benefit from favourable shocks to these countries. However, the size of the asymmetry depends both on the pervasiveness of the shock and on the exposure of a bank. We find strong evidence that sovereign shocks have a larger impact on banks when they are more pervasive and that the impact of shocks increases with exposure. However, the asymmetry of the impact of shocks is highest for banks with large exposures when shocks affect individual countries and for banks with lower exposures when shocks are pervasive. Such evidence is consistent with the market expecting government support to offset losses, but more so for losses arising within smaller countries. 


\section{References}

Acharya, V, and T. Yorulmazer, 2008, Information contagion and bank herding, Journal of Money, Credit and Banking, 40, 215-231.

Acharya, V. V., I. Drechsler, and P. Schnabl, 2014, A Pyrrhic victory? Bank bailouts and sovereign credit risk, Journal of Finance, 69, 2689-2739.

Acharya, V. V., and S. Steffen, 2015, The "greatest" carry trade ever? Understanding Eurozone bank risks, Journal of Financial Economics 115, 215-236.

Alter, A. and Y. S. Schuler, 2012, Credit spread interdependencies of European states and banks during the financial crisis, Journal of Banking and Finance, 36, 3444-3468.

Angeloni, C. and G.B. Wolff, 2012, Are banks affected by their holdings of government debt?, Bruegel working paper 2012/07.

Barth, J.R., A. Prabha, and G. Yun, 2012, The Eurozone financial crisis: The role of interdependencies between bank and sovereign risk, Journal of Financial Economic Policy, 4, 76-97.

Bekaert, G., M. Ehrmann, M. Fratzscher, and A. Mehl, 2012, Global crises and equity market contagion, mimeo.

Bank for International Settlements, 2011, The impact of sovereign credit risk on bank funding conditions, Basel.

Bolton, P., and O. Jeanne, 2011, Sovereign default risk and bank fragility in financially integrated economics, IMF Economic Review 59, 162-194.

Brunnermeier, M. K. and L.H. Pedersen, 2007, Market liquidity and funding liquidity, Review of Financial Studies.

Cocozza, E. and P. Piselli, 2011, Testing for East-West contagion in the European banking sector during the financial crisis, Banca d'Italia Working papers no. 790

Cole, R.A., and G.W. Fenn, 1994, Announcements of asset-quality problems and contagion effects in the life insurance industry, Journal of Financial Economics, 35, 181-198.

Committee on the Global Financial System, 2011, The impact of sovereign credit risk on bank funding conditions, Bank for International Settlements.

Constancio, V., 2012, Contagion and the European debt crisis, Financial Stability Review, Banque de France, 16, 109-121.

De Bruyckere, V., M. Gerhardt, G. Schepens, and R. Vander Vennet, 2012, Bank/sovereign risk spillovers in the European debt crisis, mimeo.

Demirguc-Kunt, A., and H. Huizinga, 2010, Are banks too big to fail or too big to save? International evidence from equity prices and CDS spreads, European banking center discussion paper 2010-15.

Favero, C. and F. Giavazzi, 2002, Is the international propagation of financial shocks non-linear? Evidence from the ERM, Journal of International Economics, 57, 231-246.

Fratzscher, Marcel, and Malte Rieth, 2015, Monetary policy, bank bailouts and the sovereign-bank risk nexus in the euro area, working paper, DIW Berlin. 
Gennaioli, N., A. Martin, and S. Rossi, 2013, Banks, government bonds, and defaults: What do the data say?, mimeo.

Gross, Marco, and Christoffer Kok, 2013, Measuring contagion potential among sovereigns and banks using a mixed-cross-section GVAR, working paper, ECB.

Jorion, P., and G. Zhang, 2007, Good and bad credit contagion: Evidence from credit default swaps, Journal of Financial Economics 84, 860-881.

Korte, Josef, and Sascha Steffen, 2014, Zero risk contagion - Banks' sovereign exposure and sovereign risk spillovers, unpublished working paper.

Lahmann, W., 2012, Contagion between sovereign and bank credit spreads - A global analysis of interdependencies between sovereign and bank CDS spreads, working paper, Technische Universitat Munchen. 
Figure 1. Performance of portfolios composed of banks located in core countries with high exposure (top 33\%) and low exposure (bottom 33\%) to peripheral sovereign bonds.

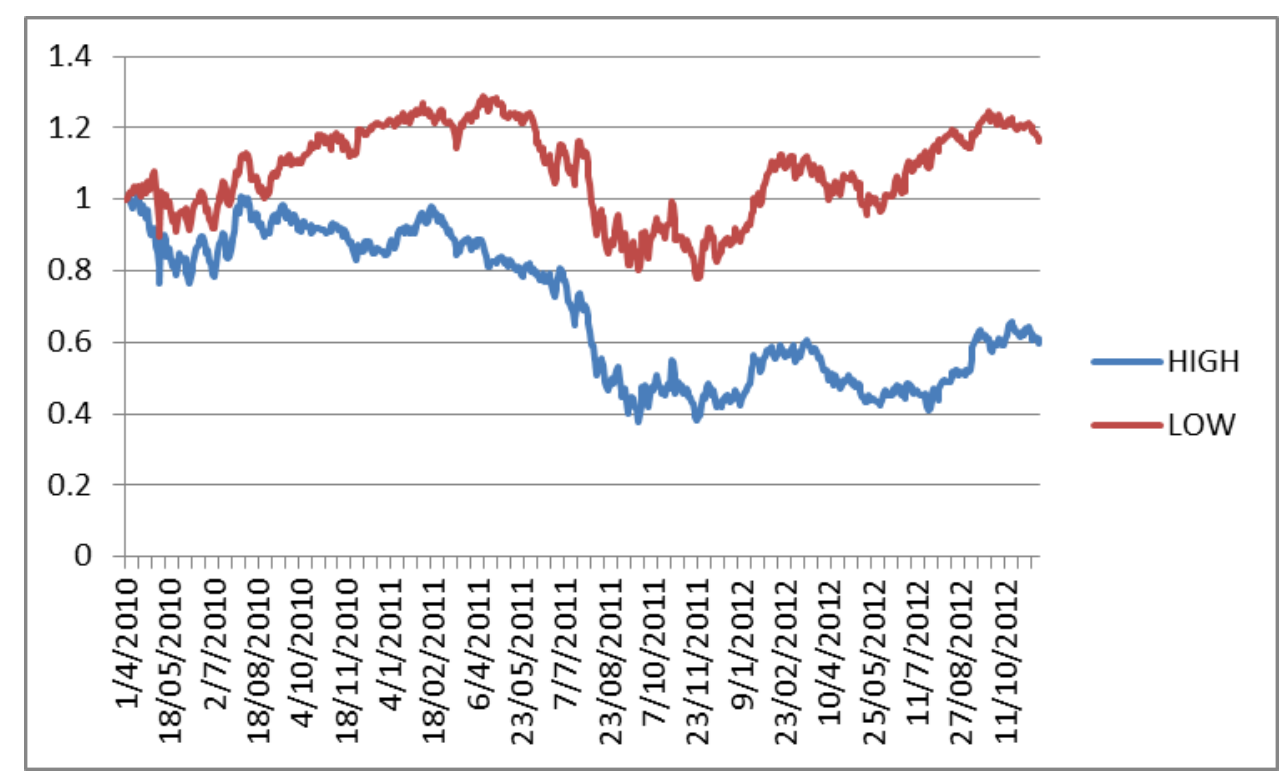

The sample of stress test banks located in core countries is ranked on the basis of available data on total net exposures (normalized by tangible equity) to the sovereign bonds of the five peripheral countries. On a given day, the country is defined as a core country if its CDS premium for a five-year contract is below the median CDS premium across countries in the sample. The high (low) exposure portfolio is composed of banks in the top (bottom) third of the empirical distribution of exposure. The portfolios are initially formed on April 1, 2010 using information released with the disclosure of the first stress test. The exposure data is revised for the dates for which exposure becomes available through stress test disclosures. The portfolios are normalized to 1 on April $1^{\text {st }}, 2010$. 
Table 1. Exposures to Peripheral Bonds

The table reports in Panels A and B the net holdings of bonds issued by a particular peripheral country as a percentage of tangible equity for banks from a peripheral country or from core countries. It also reports the exposure through derivatives as a percentage of tangible equity in Panel B. Panel A uses data released on July 23, 2010 that refer to the balance sheet at the end of March 2010 , while Panel B uses data released on October 3, 2012 that refer to the balance sheet at the end of September 2011.

Panel A. Disclosures for balance sheets as of end of March 2010.

\begin{tabular}{|l|c|r|r|r|r|r|r|}
\hline & & \multicolumn{6}{|c|}{ Net holdings of bonds issued by } \\
\hline & Number of banks & Greece & Ireland & Italy & Portugal & \multicolumn{1}{|c|}{ Spain } & \multicolumn{1}{c|}{ Total } \\
\hline Greek banks & 6 & 324.62 & 0.00 & 0.31 & 0.00 & 0.00 & 324.93 \\
\hline Irish banks & 3 & 0.19 & 29.60 & 3.43 & 1.22 & 1.85 & 36.29 \\
\hline Italian banks & 5 & 1.43 & 0.16 & 165.81 & 0.31 & 1.37 & 169.08 \\
\hline Portuguese banks & 3 & 13.34 & 6.93 & 16.66 & 91.13 & 0.31 & 128.37 \\
\hline Spanish banks & 8 & 0.69 & 0.07 & 4.41 & 3.89 & 125.49 & 134.56 \\
\hline Core banks & 21 & 5.88 & 1.79 & 19.69 & 0.93 & 4.72 & 33.03 \\
\hline
\end{tabular}

Panel B. Disclosures for balance sheets as of the end of September 2011.

\begin{tabular}{|l|l|r|r|r|r|r|r|c|c|c|c|c|c|}
\hline & & \multicolumn{4}{|c|}{ Net holdings of bonds issued by } & \multicolumn{4}{|c|}{ Exposure through derivatives towards } \\
\hline & Number of banks & Greece & Ireland & Italy & Portugal & Spain & Total & Greece & Ireland & Italy & Portugal & Spain & Total \\
\hline Greek banks & 6 & 391.82 & 0.04 & 0.17 & 0.00 & 0.00 & 392.06 & 1.83 & 0.38 & 0.00 & 0.00 & 0.00 & 2.21 \\
\hline Irish banks & 3 & 0.32 & 96.84 & 6.69 & 1.95 & 2.69 & 108.48 & -0.04 & -0.00 & 0.00 & 0.00 & 0.00 & -0.04 \\
\hline Italian banks & 5 & 1.10 & 0.11 & 193.72 & 0.50 & 2.02 & 197.45 & 0.00 & 0.00 & 0.65 & -0.01 & -0.02 & 0.62 \\
\hline Portuguese banks & 3 & 11.87 & 6.18 & 16.87 & 118.31 & 0.30 & 153.54 & 0.00 & 0.00 & 0.00 & 0.09 & 0.00 & 0.09 \\
\hline Spanish banks & 7 & 0.56 & 0.11 & 3.41 & 3.86 & 141.33 & 149.28 & -0.03 & -0.03 & 1.86 & -0.01 & 0.00 & 1.79 \\
\hline Core banks & 23 & 2.97 & 0.80 & 9.19 & 0.85 & 3.21 & 17.03 & 0.00 & 0.00 & 0.20 & 0.03 & -0.02 & 0.21 \\
\hline
\end{tabular}


Table 2. Bank stock and CDS returns.

The table reports the mean and the standard deviation of percentage daily bank stock returns and sovereign CDS returns for in the sample as well as the proportion of days a country was defined as a core country (i.e., its CDS premium was below the median CDS premium for sample countries on that day) during the period January 2010 -November 2012. The stock returns data are obtained by averaging across all the stress test banks that belong to each country.

\begin{tabular}{|c|c|c|c|c|c|c|c|}
\hline & \multicolumn{3}{|c|}{ Bank stock returns in 2010-2012 } & \multicolumn{3}{|c|}{ Country CDS returns in 2010-2012 } & \multirow{2}{*}{$\begin{array}{l}\text { Percentage of days a } \\
\text { country belongs to the } \\
\text { core }\end{array}$} \\
\hline & Number of observations & Mean & Standard deviation & Number of observations & Mean & Standard deviation & \\
\hline Austria & 1,502 & 0.02 & 3.04 & 751 & 0.00 & 4.21 & 80 \\
\hline Belgium & 1,502 & -0.17 & 4.17 & 749 & 0.16 & 4.24 & 9 \\
\hline Cyprus & 1,502 & -0.32 & 4.01 & 751 & 0.36 & 4.12 & 0 \\
\hline Denmark & 2,253 & $\begin{array}{l}-0.01 \\
\end{array}$ & 2.08 & 751 & 0.06 & 3.76 & 100 \\
\hline Finland & 751 & 0.08 & 2.23 & 751 & 0.08 & 3.54 & 100 \\
\hline France & 2,253 & -0.01 & 3.37 & 751 & 0.22 & 4.11 & 86 \\
\hline Germany & 2,927 & $\begin{array}{l}-0.01 \\
\end{array}$ & 2.39 & 751 & 0.10 & 4.07 & 100 \\
\hline Greece & 4,369 & -0.19 & 6.03 & 563 & 1.06 & 7.52 & 0 \\
\hline Hungary & 1,502 & -0.05 & 2.78 & 175 & -0.26 & 2.32 & 0 \\
\hline Ireland & 2,139 & -0.29 & 5.92 & 751 & 0.10 & 3.75 & 0 \\
\hline Italy & 3,755 & -0.11 & 3.29 & 751 & 0.25 & 4.77 & 0 \\
\hline Malta & 751 & 0.05 & 1.87 & 751 & 0.17 & 3.49 & 0 \\
\hline Netherlands & 1,502 & -0.05 & 3.15 & 751 & 0.12 & 3.77 & 100 \\
\hline Norway & 751 & 0.07 & 2.28 & 751 & 0.09 & 3.89 & 100 \\
\hline $\begin{array}{l}\text { Poland } \\
\end{array}$ & 751 & 0.03 & 2.17 & 751 & 0.02 & 3.85 & 1 \\
\hline Portugal & 3,004 & $\begin{array}{l}-0.13 \\
\end{array}$ & 2.67 & 751 & 0.37 & 4.71 & 0 \\
\hline Slovenia & 751 & -0.25 & 2.90 & 751 & 0.24 & 3.42 & 37 \\
\hline Spain & 5,395 & -0.09 & 2.98 & 749 & 0.26 & 4.68 & 0 \\
\hline Sweden & 3,004 & 0.08 & 2.14 & 751 & -0.06 & 3.57 & 100 \\
\hline UK & 3,004 & 0.04 & 2.68 & 751 & -0.07 & 3.20 & 87 \\
\hline Average across countries & 43,368 & -0.08 & 3.54 & 14,252 & 0.17 & 4.16 & \\
\hline
\end{tabular}


Table 3. Portfolio exposures to the market and to peripheral CDS returns.

The table reports results of regressions of geographical and characteristic-based portfolios on the market and CDS returns, using daily data for the period April 2010-February 2012. Core is the percentage excess return of an equally-weighted portfolio of stress test banks belonging to core countries where a country is defined as core if on a given day its CDS premium is below the median CDS premium across countries; Non-core is the percentage excess return of an equally weighted portfolio of stress test banks belonging to non-core countries, where a country is defined as non-core if on a given day its CDS premium is above the median CDS premium across countries; HML Equity core is the percentage return of an equally-weighted portfolio of stress test banks belonging to core countries with a high tangible equity capital ratio (top tertile) minus the return of equally-weighted portfolio of stress test banks belonging to core countries with a low tangible equity capital ratio (bottom tertile); HML Equity Non-core is the percentage return of an equally weighted portfolio of stress test banks belonging to non-core countries with a high tangible equity capital ratio (top tertile) minus the return of an equally-weighted portfolio of stress test banks belonging to non-core countries with a low tangible equity capital ratio (bottom tertile); Benchmark is the percentage excess return of an equally-weighted portfolio of sectors different from the financial sector of the Euro Stoxx index; Periphery CDS is an equally-weighted portfolio of CDS returns of Greece, Ireland, Italy, Portugal and Spain. P-values derived from robust standard errors in parentheses. *, **, and *** indicate statistical significance at the $10 \%$, $5 \%$, and $1 \%$ levels, respectively. The estimated coefficient is in bold whenever we can reject the null hypothesis that its value for the portfolio of non-core banks is equal to the value of the corresponding coefficient for the portfolio of core banks. The number of stars next to a coefficient in bold represent rejection of the null hypothesis at $10 \%, 5 \%, 1 \%$.

\begin{tabular}{|l|c|c|c|c|}
\hline & Core & Non-core & $\begin{array}{c}\text { HML Equity } \\
\text { Core }\end{array}$ & $\begin{array}{c}\text { HML Equity } \\
\text { Non-core }\end{array}$ \\
\hline Constant & 0.008 & $\mathbf{- 0 . 0 9 3}^{*}$ & -0.032 & -.0 .052 \\
\hline & $(0.872)$ & $\mathbf{( 0 . 1 9 7 ) ~}^{* *}$ & $(0.655)$ & $(0.442)$ \\
\hline Benchmark & 1.276 & $\mathbf{0 . 9 0 6}^{* * *}$ & -0.205 & $\mathbf{0 . 0 4 3}^{* * *}$ \\
\hline & $(0.000)$ & $(0.000)$ & $(0.005)$ & $(0.494)$ \\
\hline Periphery CDS & -0.118 & $\mathbf{- 0 . 1 9 7}^{* * *}$ & -0.020 & -0.027 \\
\hline & $(0.000)$ & $(0.000)$ & $(0.348)$ & $(0.083)$ \\
\hline Number of observations & 496 & 498 & 494 & 496 \\
\hline Adiusted $R^{2}$ & 0.777 & 0.554 & 0.012 & 0.011 \\
\hline
\end{tabular}


Table 4. Country-specific exposures.

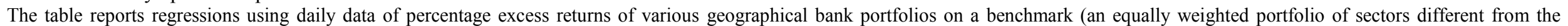

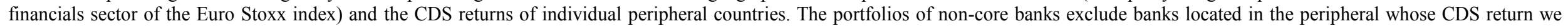

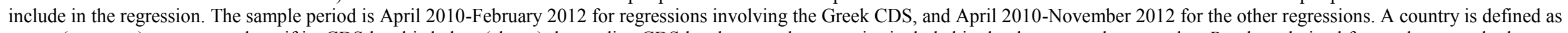

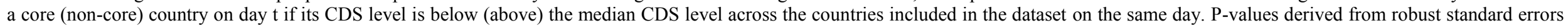

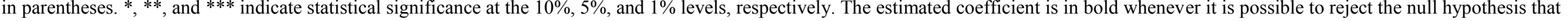
its value for the portfolio of non-core banks (excluding banks in the peripheral) is equal to the value of the corresponding coefficient for the portfolio of peripheral banks and whenever the value of the coefficient for the portfolio of non-core banks (excluding banks in the peripheral) is equal to the value of the corresponding coefficient for the portfolio of core banks. The number of stars to the

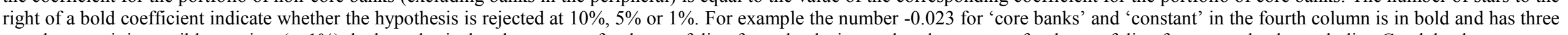
stars because it is possible to reject (at 1\%) the hypothesis that the constant for the portfolio of core banks is equal to the constant for the portfolio of non-core banks excluding Greek banks.

\begin{tabular}{|c|c|c|c|c|c|c|c|c|c|c|c|c|c|c|c|}
\hline & $\begin{array}{l}\text { Greek } \\
\text { banks }\end{array}$ & $\begin{array}{c}\text { Non-core } \\
\text { banks }\end{array}$ & $\begin{array}{l}\text { Core } \\
\text { banks }\end{array}$ & $\begin{array}{c}\text { Irish } \\
\text { banks }\end{array}$ & $\begin{array}{l}\text { Non-core } \\
\text { banks }\end{array}$ & $\begin{array}{l}\text { Core } \\
\text { banks }\end{array}$ & $\begin{array}{l}\text { Italian } \\
\text { banks }\end{array}$ & $\begin{array}{c}\text { Non-core } \\
\text { banks }\end{array}$ & $\begin{array}{l}\text { Core } \\
\text { banks }\end{array}$ & $\begin{array}{c}\text { Portugues } \\
\text { e banks }\end{array}$ & $\begin{array}{l}\text { Non-core } \\
\text { banks }\end{array}$ & $\begin{array}{c}\text { Core } \\
\text { banks }\end{array}$ & $\begin{array}{c}\text { Spanish } \\
\text { banks }\end{array}$ & $\begin{array}{c}\text { Non-core } \\
\text { banks }\end{array}$ & $\begin{array}{l}\text { Core } \\
\text { Banks }\end{array}$ \\
\hline \multirow[t]{2}{*}{ Constant } & -0.127 & -0.167 & $-0.031^{* * *}$ & -0.311 & -0.140 & $-0.029^{* *}$ & -0.085 & -0.045 & -0.011 & -0.107 & -0.036 & -0.019 & -0.056 & -0.147 & $-0.011^{* *}$ \\
\hline & $(0.551)$ & $(0.010)$ & $(0.550)$ & $(0.041)$ & $(0.028)$ & $(0.436)$ & $(0.292)$ & $(0.051)$ & $(0.762)$ & $(0.097)$ & $(0.040)$ & $(0.618)$ & $(0.298)$ & $(0.041)$ & $(0.761)$ \\
\hline \multirow{2}{*}{ Benchmark } & 1.102 & 1.157 & $1.426{ }^{* * *}$ & 1.297 & $0.930^{* * *}$ & $1.332^{* * * *}$ & 1.164 & $0.534^{* * *}$ & $1.241^{* * *}$ & 0.526 & $\mathrm{0.436}^{*}$ & $1.363^{* * *}$ & 0.692 & $0.902^{* * * *}$ & $1.262^{* * * *}$ \\
\hline & $\begin{array}{l}(0.000) \\
\end{array}$ & $\begin{array}{l}(0.000) \\
\end{array}$ & $\begin{array}{l}(0.000) \\
\end{array}$ & $(0.000)$ & $\begin{array}{l}(0.000) \\
\end{array}$ & $(0.000)$ & $(0.000)$ & $(0.000)$ & $\begin{array}{l}(0.000) \\
\end{array}$ & $(0.000)$ & $(0.000)$ & $\begin{array}{l}(0.000) \\
\end{array}$ & $\begin{array}{l}(0.000) \\
\end{array}$ & $(0.000)$ & $\begin{array}{l}(0.000) \\
\end{array}$ \\
\hline \multirow[t]{2}{*}{ Greek $C D S$} & -0.131 & $-0.0266^{* * * *}$ & -0.027 & & & & & & & & & & & & \\
\hline & $(0.002)$ & $(0.016)$ & $(0.007)$ & & & & & & & & & & & & \\
\hline \multirow[t]{2}{*}{ Irish CDS } & & & & -0.189 & -0.199 & $-0.109^{* * * *}$ & & & & & & & & & \\
\hline & & & & $(0.000)$ & $(0.000)$ & $(0.000)$ & & & & & & & & & \\
\hline \multirow[t]{2}{*}{ Italian CDS } & & & & & & & -0.258 & $\mathbf{- 0 . 0 8 3}^{* * * *}$ & $-0.113^{* * * *}$ & & & & & & \\
\hline & & & & & & & $(0.000)$ & $(0.000)$ & $(0.000)$ & & & & & & \\
\hline \multirow[t]{2}{*}{$\begin{array}{l}\text { Portuguese } \\
C D S\end{array}$} & & & & & & & & & & -0.149 & $-0.043^{* * *}$ & $-0.074^{* * * *}$ & & & \\
\hline & & & & & & & & & & $(0.000)$ & $(0.000)$ & $(0.000)$ & & & \\
\hline \multirow[t]{2}{*}{ Spanish CDS } & & & & & & & & & & & & & -0.162 & -0.188 & $-0.111^{* * *}$ \\
\hline & & & & & & & & & & & & & $(0.000)$ & $(0.000)$ & $(0.000)$ \\
\hline $\begin{array}{l}\text { Number of } \\
\text { observations }\end{array}$ & 499 & 498 & 496 & 687 & 685 & 683 & 687 & 687 & 683 & 687 & 687 & 683 & 687 & 685 & 683 \\
\hline Adjusted $R^{2}$ & 0.123 & 0.543 & 0.739 & .187 & .462 & .766 & .537 & .687 & .783 & .290 & .643 & .754 & .478 & .437 & .779 \\
\hline
\end{tabular}


Table 5. Regressions of long-short exposure portfolios.

The table reports regressions of daily returns in percent of long-short exposure portfolios on a benchmark (an equally weighted portfolio of sectors different from the financials sector of the Euro Stoxx index) and the CDS returns of individual peripheral countries. Exposure is measured as the ratio between net holdings of government bonds and tangible equity. In Panel A exposure is attributed starting from the date of the balance sheet provided in the stress tests whereas in Panel B exposure is attributed starting on the day of disclosure of the stress test data. The sample period is April 2010-February 2012 for regressions involving the Greek CDS, and April 2010-November 2012 for the other regressions. A core (non-core) country on a given day is a country whose CDS premium is below (above) the median CDS premium across the countries included in the dataset. The long portfolio has banks in the top tertile of exposure and the short portfolios has banks in the bottom tertile of exposure using the most recent exposure data available. For the non-core portfolios, we exclude banks from the country whose CDS is included in the regression. Benchmark is the percentage excess return of an equally-weighted portfolio of sectors different from the financial sector of the Euro Stoxx index. *,**, and *** indicate statistical significance at the $10 \%, 5 \%$, and $1 \%$ levels, respectively. Estimated coefficients are in bold whenever there is a rejection of the hypothesis that the sensitivity to a peripheral CDS of the long-short portfolio of core banks exposed to a peripheral is equal to the sensitivity of the long-short portfolio of non-core banks exposed to the same peripheral. The number of stars next to the bold coefficient indicates rejection at $10 \%, 5 \%, 1 \%$.

Panel A. Exposure attributed using the balance sheet date approach.

\begin{tabular}{|c|c|c|c|c|c|c|c|c|c|c|}
\hline & \multicolumn{5}{|c|}{ Long-short portfolios of core banks exposed to: } & \multicolumn{5}{|c|}{$\begin{array}{l}\text { Long-short portfolios of non-core banks, excluding banks from country towards } \\
\text { which exposure is computed, exposed to: }\end{array}$} \\
\hline & Greece & Ireland & Italy & Portugal & Spain & Greece & Ireland & Italy & Portugal & Spain \\
\hline \multirow[t]{2}{*}{ Constant } & -0.000 & -0.032 & -0.049 & -0.037 & -0.049 & 0.071 & 0.039 & 0.070 & 0.072 & 0.082 \\
\hline & $(0.993)$ & $(0.429)$ & $(0.314)$ & $(0.420)$ & $(0.298)$ & $(0.357)$ & $(0.471)$ & $(0.372)$ & $(0.520)$ & $(0.312)$ \\
\hline \multirow[t]{2}{*}{ Benchmark } & 0.147 & 0.280 & 0.366 & 0.483 & 0.285 & 0.269 & 0.204 & $0.576^{* * *}$ & $\mathbf{0 . 7 6 8}^{* * *}$ & $0.483^{* *}$ \\
\hline & $(0.000)$ & $(0.000)$ & $(0.000)$ & $(0.000)$ & $(0.006)$ & $(0.000)$ & $(0.000)$ & $(0.000)$ & $(0.000)$ & $(0.000)$ \\
\hline \multirow[t]{2}{*}{ Greek CDS } & -0.013 & & & & & $-0.041^{* *}$ & & & & \\
\hline & $(0.299)$ & & & & & $(0.002)$ & & & & \\
\hline \multirow[t]{2}{*}{ Irish CDS } & & -0.045 & & & & & -0.029 & & & \\
\hline & & $(0.000)$ & & & & & $(0.070)$ & & & \\
\hline \multirow[t]{2}{*}{ Italian $C D S$} & & & -0.058 & & & & & -0.088 & & \\
\hline & & & $(0.000)$ & & & & & $(0.000)$ & & \\
\hline \multirow[t]{2}{*}{ Portuguese CDS } & & & & -0.047 & & & & & $0.020^{* * *}$ & \\
\hline & & & & $(0.001)$ & & & & & $(0.425)$ & \\
\hline \multirow[t]{2}{*}{ Spanish CDS } & & & & & -0.048 & & & & & -0.033 \\
\hline & & & & & $(0.001)$ & & & & & $\begin{array}{l}(0.143) \\
\end{array}$ \\
\hline Number of observations & 495 & 683 & 682 & 682 & 682 & 495 & 681 & 680 & 680 & 683 \\
\hline Adjusted $R^{2}$ & 0.148 & 0.134 & 0.192 & 0.246 & 0.138 & 0.079 & 0.040 & 0.186 & 0.081 & 0.086 \\
\hline
\end{tabular}


Panel B. Exposure attributed using the disclosure date approach

\begin{tabular}{|c|c|c|c|c|c|c|c|c|c|c|}
\hline & \multicolumn{5}{|c|}{ Long-short portfolios of core banks exposed to: } & \multicolumn{5}{|c|}{$\begin{array}{l}\text { Long-short portfolios of non-core banks, excluding banks from country towards } \\
\text { which exposure is computed, exposed to: }\end{array}$} \\
\hline & Greece & Ireland & Italy & Portugal & Spain & Greece & Ireland & Italy & Portugal & Spain \\
\hline \multirow[t]{2}{*}{ Constant } & 0.000 & -0.052 & -0.018 & -0.024 & -0.025 & -0.047 & 0.004 & 0.093 & 0.081 & 0.070 \\
\hline & $(0.993)$ & $(0.186)$ & $(0.724)$ & $(0.616)$ & $(0.614)$ & $(0.581)$ & $(0.950)$ & $(0.237)$ & $(0.355)$ & $(0.489)$ \\
\hline \multirow[t]{2}{*}{ Benchmark } & 0.147 & 0.216 & 0.296 & 0.477 & 0.195 & $-0.124^{* * *}$ & $-0.043^{* * *}$ & 0.342 & $0.110^{* * * *}$ & $0.479^{* * * *}$ \\
\hline & $(0.022)$ & $(0.000)$ & $(0.000)$ & $(0.000)$ & $(0.001)$ & $(0.144)$ & $(0.505)$ & $(0.000)$ & $(0.270)$ & $(0.000)$ \\
\hline \multirow[t]{2}{*}{ Greek CDS } & -0.013 & & & & & $-0.033^{*}$ & & & & \\
\hline & $(0.299)$ & & & & & $(0.013)$ & & & & \\
\hline \multirow[t]{2}{*}{ Irish CDS } & & -0.078 & & & & & $-0.012^{* *}$ & & & \\
\hline & & $(0.000)$ & & & & & $(0.548)$ & & & \\
\hline \multirow[t]{2}{*}{ Italian CDS } & & & -0.083 & & & & & -0.083 & & \\
\hline & & & $(0.002)$ & & & & & $(0.000)$ & & \\
\hline \multirow[t]{2}{*}{ Portuguese CDS } & & & & -0.067 & & & & & $\mathbf{0 . 0 2 2}^{* * *}$ & \\
\hline & & & & $(0.000)$ & & & & & $(0.401)$ & \\
\hline \multirow[t]{2}{*}{ Spanish CDS } & & & & & -0.099 & & & & & -0.064 \\
\hline & & & & & $(0.000)$ & & & & & $(0.029)$ \\
\hline Number of observations & 415 & 597 & 596 & 597 & 597 & 415 & 595 & 595 & 596 & 595 \\
\hline Adjusted $R^{2}$ & 0.029 & 0.140 & 0.182 & 0.237 & 0.159 & 0.020 & -0.002 & 0.096 & -0.000 & 0.071 \\
\hline
\end{tabular}


Table 6. Frequency of CDS tail returns.

The table reports the number of times a peripheral country has a negative CDS tail return in Panel A and a positive CDS tail return in Panel B conditional on how many other peripheral countries

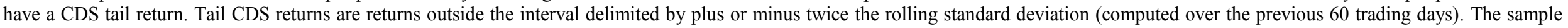
period is April 2010-February 2012.

Panel A. Negative tail CDS returns

\begin{tabular}{|c|c|c|c|c|c|c|}
\hline & Greece & Ireland & Italy & Portugal & Spain & $\begin{array}{c}\text { Total number of tail } \\
\text { returns conditional on the } \\
\text { number of countries with } \\
\text { tail returns reported in the rows }\end{array}$ \\
\hline $\begin{array}{c}\text { Number of other peripheral countries } \\
\text { with simultaneous tail CDS returns }\end{array}$ & 10 & 3 & 1 & 1 & 0 & 15 \\
\hline 0 & 2 & 2 & 1 & 1 & 2 & 8 \\
\hline 1 & 1 & 2 & 2 & 3 & 4 & 12 \\
\hline 2 & 1 & 1 & 0 & 1 & 1 & 4 \\
\hline 3 & 2 & 2 & 2 & 2 & 2 & 10 \\
\hline 4 & 16 & 10 & 6 & 8 & 9 & 49 \\
\hline Total number of tail returns & & & & & \\
\hline
\end{tabular}

Panel B: positive tail CDS returns.

\begin{tabular}{|c|c|c|c|c|c|c|}
\hline & Greece & Ireland & Italy & Portugal & Spain & $\begin{array}{c}\text { Total number of tail } \\
\text { returns conditional on the } \\
\text { number of countries with } \\
\text { tail returns reported in the rows }\end{array}$ \\
\hline $\begin{array}{c}\text { Number of other peripheral countries } \\
\text { with simultaneous tail CDS returns }\end{array}$ & 15 & 4 & 6 & 5 & 2 & 32 \\
\hline 0 & 5 & 3 & 4 & 6 & 6 & 24 \\
\hline 1 & 1 & 3 & 2 & 1 & 2 & 9 \\
\hline 2 & 4 & 6 & 5 & 5 & 4 & 24 \\
\hline 3 & 3 & 3 & 3 & 3 & 3 & 15 \\
\hline 4 & 28 & 19 & 20 & 22 & 17 & 104 \\
\hline Total number of tail returns & & & & & & \\
\hline
\end{tabular}


Table 7. CDS and bank returns on CDS tail event days.

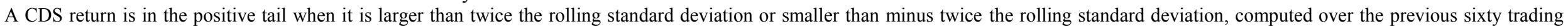

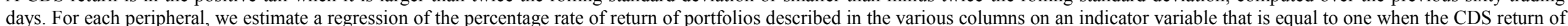
the country specified in the first column is in the positive tail and an indicator variable that is equal to one when the CDS return is in the negative tail. Except for Greece, the sample includes all tail return days from April 2010 to November 2012. With Greece, the sample stops in February 2012. The regressions for stock portfolios also control for the benchmark (an equally weighted portfolio of sectors the non- financial sectors of the Euro Stoxx index).*,**, and *** indicate rejection of the null hypothesis that each abnormal return is equal to zero at the $10 \%, 5 \%$, and $1 \%$ levels, respectively. In each case we also report the p-value of the test that the abnormal return for the positive tail dummy is equal to minus the abnormal return for the negative tail dummy. For the $\mathrm{p}$ value, * **, and *** indicate rejection of the null hypothesis that the absolute value of the two abnormal returns are equal at the $10 \%, 5 \%$, and $1 \%$ levels, respectively. A country is defined as a core country on a day when its CDS level is below the median CDS across the countries in our sample. The different portfolios are described as follows. 'CDS return of the peripheral in the tail' is the CDS return of the peripherals in the various rows, 'CDS return of core countries' is the average CDS returns across core countries, 'Banks in core countries' is the excess return of an equallyweighted portfolios of banks located in core countries, 'CDS return of non-core countries' is the average CDS return of non-core countries excluding the peripheral indicated in the different rows, 'Banks in noncore countries' is the excess return of an equally-weighted portfolios of banks located in a non-core country excluding banks located in the peripheral country indicated in the row of the table, 'Banks located in the peripheral in the tail' is the excess return of an equally weighted portfolio of the banks located in the peripheral country described in the row of the table, 'Long-short exposure portfolio of banks located in core countries' is the return of a portfolio that is long banks located in core countries whose exposure is in the third tertile of the exposure distribution and short banks whose exposure is in the first tertile of the exposure distribution, 'Long-short exposure portfolio of banks located in noncore countries' is the return of a portfolio that is long banks located in noncore countries (excluding the peripheral country in the row of the table) whose exposure is in the third tertile of the exposure distribution and short banks located in noncore countries (excluding the peripheral country in the row of the table) whose exposure is in the first tertile of the exposure distribution. In panel A we condition on at least the CDS of one peripheral country being in the tail. In panel B we condition on the CDS of a peripheral country being in the tail when the CDS of no other peripheral is in the tail on the same day.

Panel A. Sample includes only days when at least one peripheral CDS is in either the positive or the negative tail.

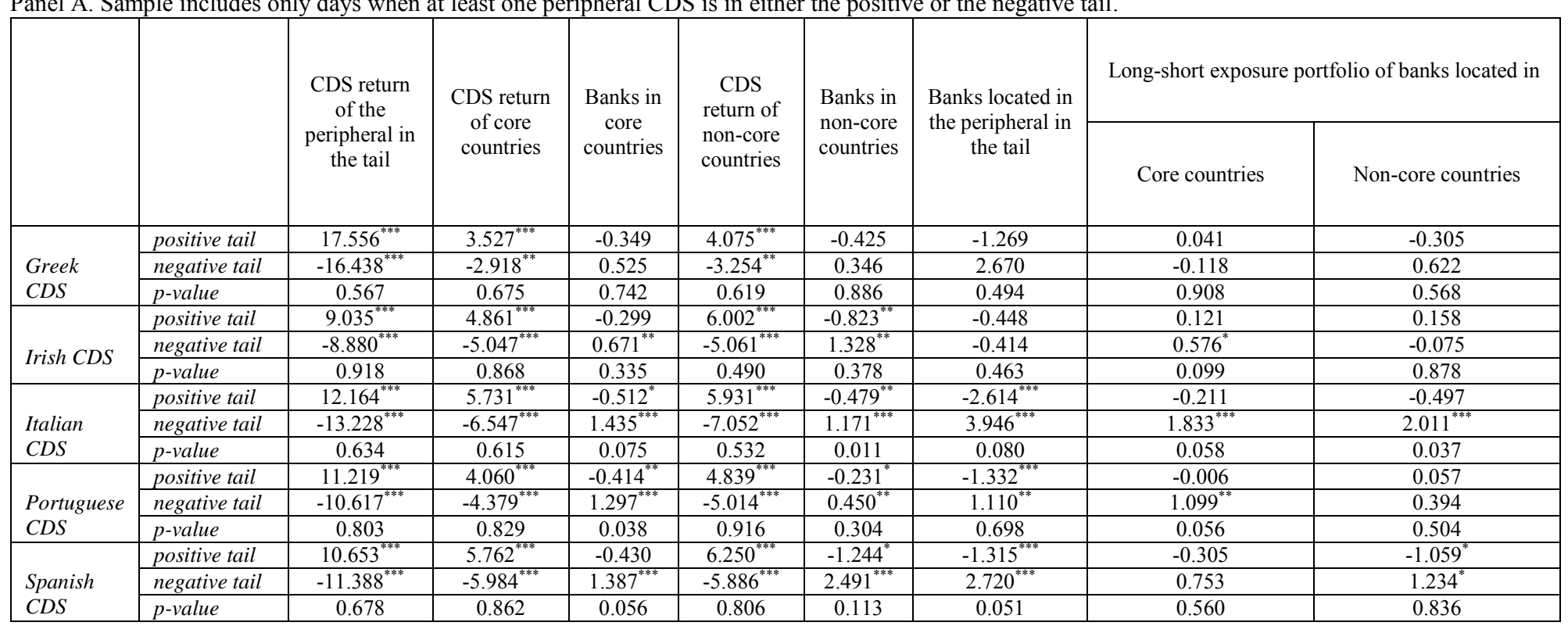


Panel B. Sample includes only days when at most one peripheral CDS is in either the positive or the negative tail.

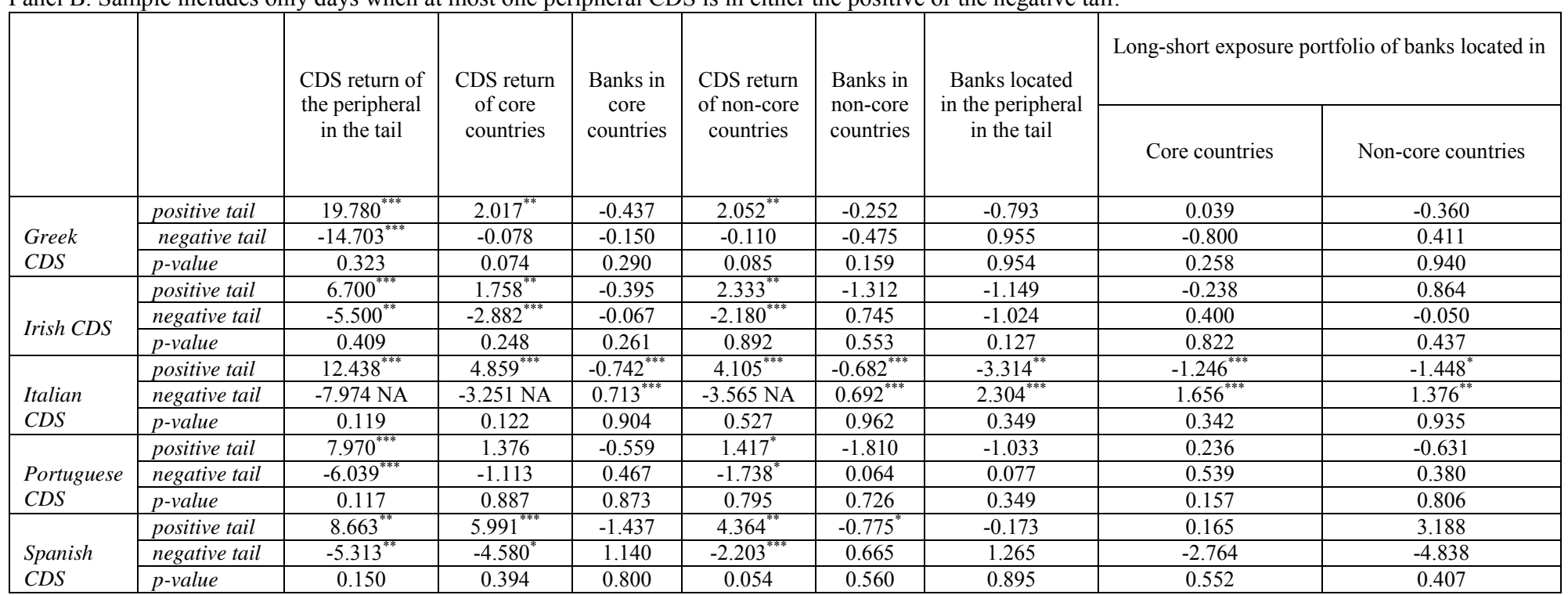


Table 8. Indicator variable regressions

The table reports the results of regressions of portfolio percentage excess returns on a constant, the benchmark, and indicator variables for the number of peripheral countries whose CDS are in their respective tails on a given day. Positive (negative) tail indicator counts the number of peripheral countries whose CDS return is in the positive (negative) tail. The sample includes only tail days. The first portfolio is an equally weighted portfolio of stress test banks located in all countries, the second portfolio is an equally weighted portfolio of stress test banks located in core countries, the third is an equally weighted portfolio of stress test banks located in non-core countries excluding the banks located in a peripheral country with a tail CDS realization on a given day, the fourth is an equally weighted portfolio of stress test banks located in the peripheral country with a tail outcome on a given day. On a given day a country is defined as a core (non-core) country if its CDS level is below (above) the median CDS level across the countries considered in the sample. The regression is run only on days of tail returns over the sample period April 2010-November 2012. P-values obtained from robust standard errors in parentheses. * ${ }^{* *}$, and $* * *$ indicate statistical significance at the $10 \%, 5 \%$, and $1 \%$ levels, respectively.

\begin{tabular}{|c|c|c|c|c|c|c|c|c|c|c|c|c|}
\hline & \multicolumn{3}{|c|}{ Banks located in all countries } & \multicolumn{3}{|c|}{ Banks located in core countries } & \multicolumn{3}{|c|}{ Banks located in non-core countries } & \multicolumn{3}{|c|}{$\begin{array}{l}\text { Banks located in peripheral } \\
\text { countries with tail outcome }\end{array}$} \\
\hline & 1 & 2 & 3 & 1 & 2 & 3 & 1 & 2 & 3 & 1 & 2 & 3 \\
\hline Constant & $-0.393^{*}$ & $-1.103^{* *}$ & -0.221 & $-0.492^{* *}$ & -0.420 & $-0.302^{* *}$ & -0.430 & $-1.604^{* *}$ & -0.192 & -0.530 & -2.012 & -0.309 \\
\hline Positive tail indicator & $-0.237^{* *}$ & 0.821 & & -0.073 & 0.142 & & -0.183 & $1.489^{*}$ & & $-0.421^{*}$ & 1.096 & \\
\hline Negative tail indicator & $0.820^{* * *}$ & 1.089 & & $0.711^{* * *}$ & 0.094 & & $0.874^{* * *}$ & $1.462^{*}$ & & $1.072^{* * *}$ & $2.884^{* *}$ & \\
\hline Positive tail indicator squared & & $-0.234^{* *}$ & $-0.092^{* * *}$ & & -0.076 & $-0.049^{* * *}$ & & $-0.364^{* *}$ & $-0.092^{* * *}$ & & -0.276 & $-0.122^{* * *}$ \\
\hline Negative tail indicator squared & & 0.003 & $0.220^{* * *}$ & & $0.183^{* *}$ & $0.199^{* * *}$ & & -0.039 & $0.237^{* * *}$ & & -0.382 & $0.237^{* * * *}$ \\
\hline Number of observations & 113 & 113 & 113 & 113 & 113 & 113 & 113 & 113 & 113 & 113 & 113 & 113 \\
\hline Adusted-R2 & 0.806 & 0.820 & 0.816 & 0.874 & 0.891 & 0.891 & 0.632 & 0.660 & 0.652 & 0.409 & 0.405 & 0.389 \\
\hline $\begin{array}{l}\text { p-value for test of equality of } \\
\text { the absolute value of the } \\
\text { coefficients of the linear terms }\end{array}$ & 0.003 & 0.055 & & 0.002 & 0.742 & & 0.017 & 0.045 & & 0.157 & 0.129 & \\
\hline $\begin{array}{l}\text { p-value for test of equality of } \\
\text { the absolute value of the } \\
\text { coefficients of the quadratic } \\
\text { terms }\end{array}$ & & 0.214 & 0.000 & & 0.413 & 0.000 & & 0.150 & 0.009 & & 0.165 & 0.236 \\
\hline
\end{tabular}


Table 9. Summary statistics.

The table reports summary statistics about bank characteristics and CDS for all the banks (the 60 listed banks in the stress tests) and CDS included in our sample. Equity is the percentage ratio between tangible equity (equity minus intangible assets minus other intangibles) and assets, Fragility is defined as one hundred minus the percentage ratio between customer deposits and the sum of total deposits and short-term funding. Log assets is the log of total assets in units of billion euros. Total exposure to peripherals over total assets is the percentage ratio between the total exposure to peripherals and total assets. Peripheral CDS return on positive tail days is the average CDS percentage return across peripheral countries on days where at least one peripheral country has a positive CDS tail realization, Peripheral CDS return on negative tail days is the average CDS percentage return across peripheral countries on days where at least one peripheral country has a negative CDS tail realization, Core CDS return on positive tail days is the average CDS percentage return across core countries on days where at least one peripheral country has a positive CDS tail realization, Core CDS return on negative tail days is the average CDS percentage return across core countries on days where at least one peripheral country has a negative CDS tail realization. Peripheral countries include Greece, Ireland, Italy, Portugal and Spain. Core (non-core) countries on a given day are the countries whose CDS premium is below (above) the median CDS premium across all the countries in our sample. The coefficient for the mean of equity, fragility, log assets and total exposure is in bold whenever it is possible to reject the hypothesis that the means for core and noncore countries are equal. The coefficient for the mean of CDS returns is in bold whenever it is possible to reject the hypothesis that the absolute values of the means for positive tail days and negative tail days are equal. $* * *$, and $* * *$ indicate statistical significance at the $10 \%, 5 \%$, and $1 \%$ levels, respectively.

\begin{tabular}{|l|c|c|c|c|}
\hline & Mean & $\begin{array}{c}\text { Standard } \\
\text { deviation }\end{array}$ & Minimum & Maximum \\
\hline Equity & 4.616 & 2.249 & -5.553 & 12.697 \\
\hline Equity of banks in core countries & 3.828 & 1.557 & -0.364 & 11.370 \\
\hline Equity of banks in non-core countries & $\mathbf{5 . 1 5 1}^{* * * *}$ & 2.451 & -5.553 & 12.697 \\
\hline Fragility & 28.879 & 13.256 & 0.000 & 91.280 \\
\hline Fragility of banks in core countries & 30.290 & 12.995 & 0.000 & 91.280 \\
\hline Fragility of banks in non-core countries & $\mathbf{2 8 . 1 3 0}$ & 13.017 & 0.000 & 91.280 \\
\hline Log assets & 5.073 & 1.552 & 0.963 & 7.788 \\
\hline Log assets of banks in core countries & 5.838 & 1.404 & 1.755 & 7.736 \\
\hline Log assets of banks in non-core countries & $\mathbf{4 . 4 9 7}^{* * * *}$ & 1.374 & 0.963 & 7.788 \\
\hline Total exposure to peripherals over total assets, all banks & 4.057 & 5.831 & 0.000 & 34.039 \\
\hline Total exposure to peripherals over total assets, banks in core countries & 0.452 & 0.619 & 0.000 & 3.345 \\
\hline Total exposure to peripherals over total assets, banks in non-core countries & $\mathbf{7 . 1 9 9}$ & 6.499 & 0.000 & 34.039 \\
\hline Peripheral CDS return on positive tail days & 6.857 & 6.606 & -10.285 & 72.562 \\
\hline Peripheral CDS return on negative tail days & -6.701 & 7.279 & -38.913 & 6.741 \\
\hline Core CDS return on positive tail days & 3.752 & 4.103 & -13.538 & 25.789 \\
\hline Core CDS return on negative tail days & $\mathbf{- 3 . 0 3 7}$ & 4.509 & -26.693 & 11.088 \\
\hline
\end{tabular}


Table 10: Tail regressions.

The regressions of daily abnormal returns on days with CDS tail returns in percents (obtained as residuals from a market model estimated over the previous 60 days where the market is represented by the equal average of the sectors of the Stoxx index excluding banks, insurance companies and financial institutions) on bank and country characteristics measured as of the end of the previous quarter. The sample period is April 2010-November 2012. The sample includes all the banks in the stress tests that are publicly traded and report sovereign bond holdings except that in panel D only banks from the Eurozone are included. Firm characteristics are computed using end-of-quarter data. Equity is equity minus (if available) intangible assets divided by total assets. Fragility is defined as one minus the ratio between customer deposits and the sum of total deposits and short-term funding. The bank variables are winsorized at the $1 \%$ and $99 \%$ levels and are expressed in percentage terms. Exposure is the ratio between exposure to a tail peripheral country and total assets. On a given day, a tail peripheral country is defined as a country where the CDS return is larger (positive tail) than two rolling standard deviations (measured over the previous 60 trading days) or lower (negative tail) than minus two rolling standard deviations (measured over the previous 60 trading

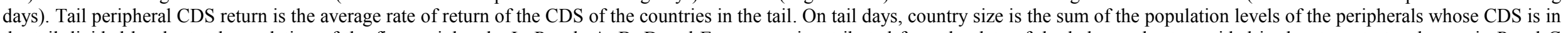
the tail divided by the total population of the five peripherals. In Panels A, B, D and E exposure is attributed from the date of the balance sheet provided in the stress tests whereas in Panel C exposure is attributed from the day of disclosure of the stress test data. In Panels A, B, C and E we condition on at least one peripheral having CDS tail realization whereas in Panel D we condition on exactly one peripheral having a CDS tail realization. Standard errors are obtained by clustering at the bank's country level. ${ }^{*},{ }^{* *}$, and ${ }^{* * *}$ indicate statistical significance at the $10 \%, 5 \%$, and $1 \%$

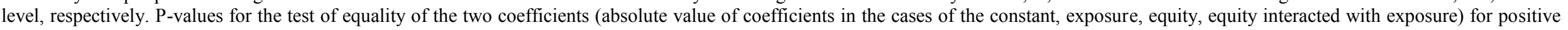
and negative tail days are in parentheses.

Panel A. Regressions conditional on at least one peripheral having a tail realization, using balance sheet exposure.

\begin{tabular}{|c|c|c|c|c|c|c|c|}
\hline & 1 & 2 & 3 & 4 & 5 & 6 & 7 \\
\hline Constant for positive tail days & $-0.455^{* * *}$ & $-0.222^{* *}$ & $-0.398^{* * *}$ & $-0.174^{* *}$ & $-0.172^{* *}$ & $-0.542^{* * *}$ & $-0.223^{*}$ \\
\hline \multirow{2}{*}{ Constant for negative tail days } & $0.634^{* * *}$ & 0.289 & $0.561^{* * *}$ & $0.327^{*}$ & $0.352^{*}$ & $0.748^{* * *}$ & $0.408^{*}$ \\
\hline & $(0.094)$ & $(0.743)$ & $(0.115)$ & $(0.402)$ & $(0.349)$ & $(0.376)$ & $(0.382)$ \\
\hline Tail peripheral CDS return on positive tail days & & $-0.019^{* * * 4}$ & & $-0.018^{* * * *}$ & $-0.018^{* * * *}$ & & \\
\hline \multirow[t]{2}{*}{ Tail peripheral CDS return on negative tail days } & & $-0.033^{* *}$ & & -0.026 & -0.020 & & \\
\hline & & $(0.366)$ & & $(0.763)$ & $(0.881)$ & & \\
\hline Exposure on positive tail days & & & $-25.962^{* *}$ & $-25.243^{* *}$ & $-24.793^{* *}$ & $-33.581^{* * *}$ & $-27.853^{* *}$ \\
\hline \multirow[t]{2}{*}{ Exposure on negative tail days } & & & $41.840^{* * *}$ & $39.934^{* * *}$ & $31.785^{* *}$ & $42.597^{* *}$ & $42.108^{* * *}$ \\
\hline & & & $(0.018)$ & $(0.019)$ & $(0.268)$ & $(0.507)$ & $(0.113)$ \\
\hline Exposure $\times$ Tail peripheral CDS return on positive tail days & & & & & -23.133 & & \\
\hline \multirow[t]{2}{*}{ Exposure $\times$ Tail peripheral CDS return on negative tail days } & & & & & $-237.911^{* * *}$ & & \\
\hline & & & & & $(0.004)$ & & \\
\hline Equity on positive tail days & & & & & & 3.587 & \\
\hline \multirow[t]{2}{*}{ Equity on negative tail days } & & & & & & -3.913 & \\
\hline & & & & & & $(0.936)$ & \\
\hline Equity $\times$ Exposure on positive tail days & & & & & & $1107.353^{* * *}$ & \\
\hline \multirow[t]{2}{*}{ Equity $\times$ Exposure on negative tail days } & & & & & & -145.617 & \\
\hline & & & & & & $(0.193)$ & \\
\hline Fragility on positive tail days & & & & & & & -0.620 \\
\hline \multirow[t]{2}{*}{ Fragility on negative tail days } & & & & & & & 0.548 \\
\hline & & & & & & & $(0.922)$ \\
\hline Fragility $\times$ Exposure on positive tail days & & & & & & & -70.978 \\
\hline \multirow[t]{2}{*}{ Fragility $\times$ Exposure on negative tail days } & & & & & & & 2.263 \\
\hline & & & & & & & $(0.519)$ \\
\hline Number of observations & 4,827 & 4,827 & 4,308 & 4,308 & 4,308 & 4,308 & 4,308 \\
\hline Adjusted- $R^{2}$ & 0.030 & 0.034 & 0.056 & 0.060 & 0.062 & 0.059 & 0.058 \\
\hline
\end{tabular}


Panel B. Regressions conditional on at least one peripheral having a tail realization, using balance sheet exposure.

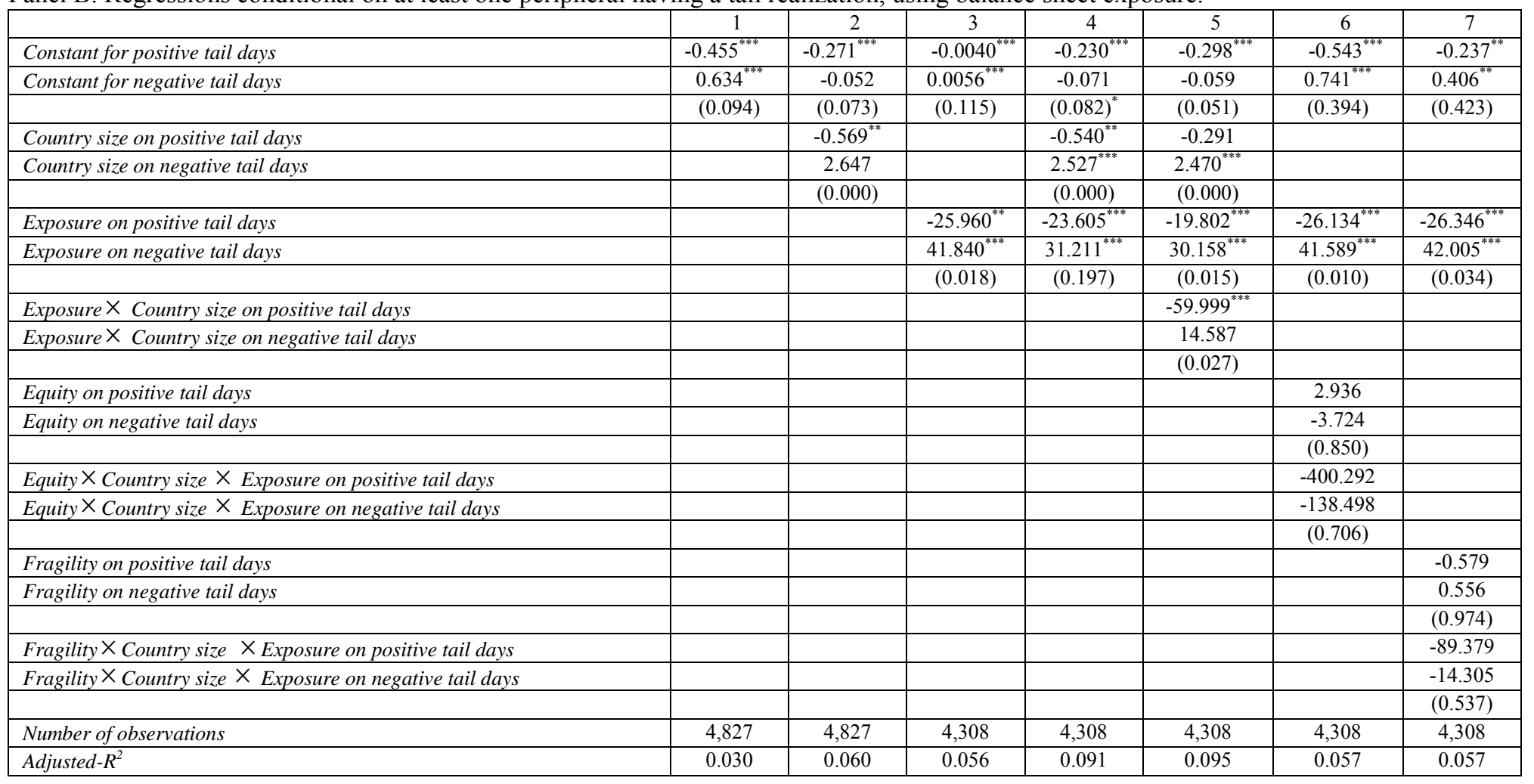


Panel C. Regressions conditional on at least one peripheral having a tail realization, using exposure at disclosure.

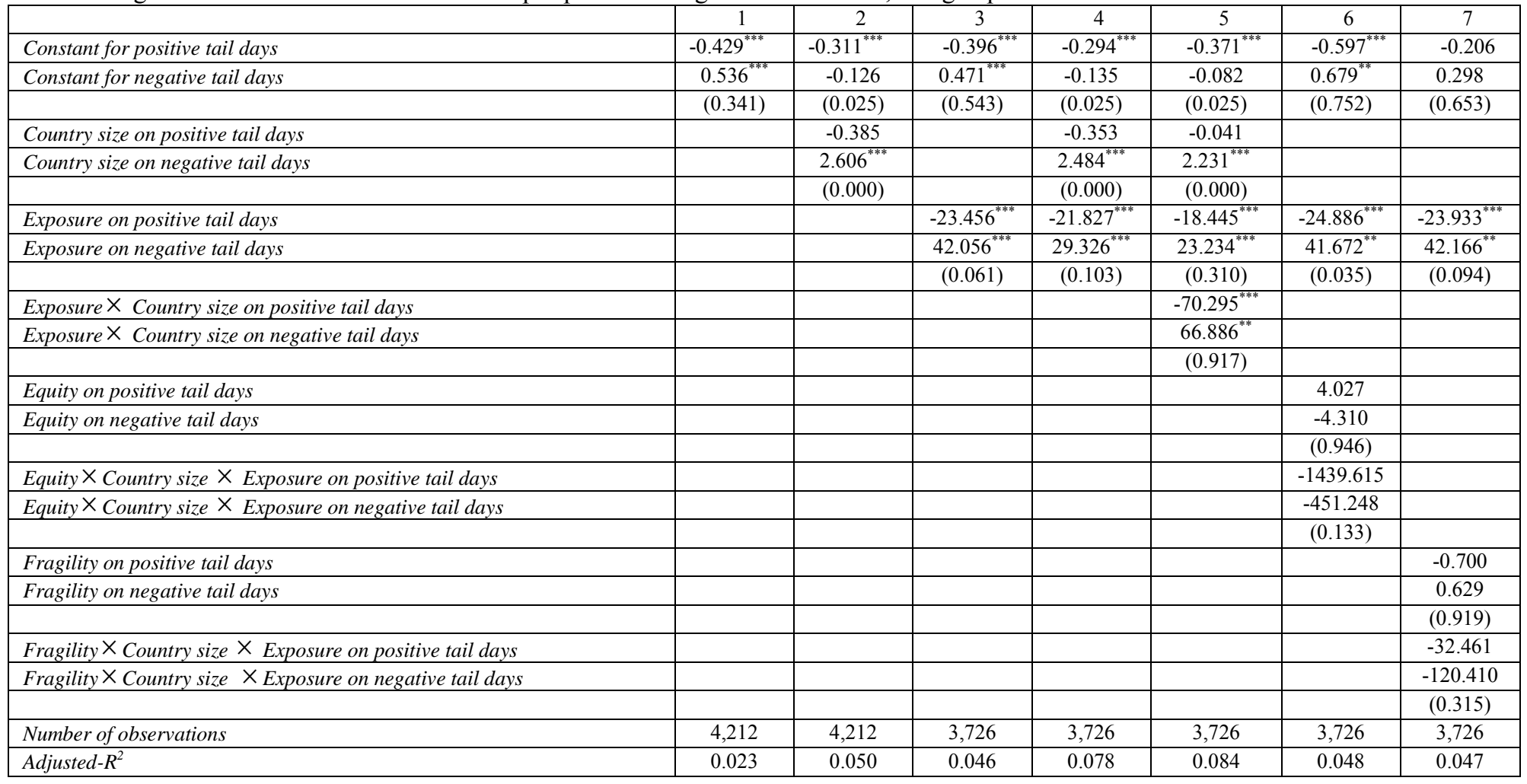


Panel D. Regressions conditional on one peripheral having a tail realization, using balance sheet exposure.

\begin{tabular}{|c|c|c|c|c|c|c|c|}
\hline & 1 & 2 & 3 & 4 & 5 & 6 & 7 \\
\hline \multirow[t]{2}{*}{ Constant for negative tail days } & 0.088 & $0.324^{* *}$ & 0.063 & $0.349^{* *}$ & $0.554^{* * *}$ & 0.562 & -0.121 \\
\hline & $(0.013)$ & $(0.654)$ & $(0.022)$ & $(0.450)$ & $(0.138)$ & $(0.908)$ & $(0.134)$ \\
\hline Tail peripheral CDS return on positive tail days & & $-0.015^{* * *}$ & & $-0.016^{* * *}$ & $-0.017^{* * *}$ & & \\
\hline Tail peripheral CDS return on negative tail days & & $(0.016)$ & & $(0.008)$ & $(0.703)$ & & \\
\hline Exposure on positive tail days & & & -5.475 & -4.533 & $-24.498^{* *}$ & $-36.324^{* * *}$ & -4.307 \\
\hline Exposure on negative tail days & & & $24.514^{* * *}$ & $26.269^{* * *}$ & $28.602^{* *}$ & $40.354^{* *}$ & $23.066^{* * *}$ \\
\hline \multirow[t]{2}{*}{ Exposure $\times$ Tail peripheral CDS return on negative tail days } & & & & & $-260.731^{* * *}$ & & \\
\hline & & & & & $(0.003)$ & & \\
\hline Equity on positive tail days & & & & & & 3.224 & \\
\hline \multirow[t]{2}{*}{ Equity on negative tail days } & & & & & & 1.831 & \\
\hline & & & & & & $(0.482)$ & \\
\hline Equity $\times$ Exposure on positive tail days & & & & & & $1162.543^{* * *}$ & \\
\hline Fragility $\times$ Exposure on positive tail days & & & & & & & 39.703 \\
\hline \multirow[t]{2}{*}{ Fragility $\times$ Exposure on negative tail days } & & & & & & & -45.237 \\
\hline & & & & & & & $(0.952)$ \\
\hline Number of observations & 3,011 & 3,011 & 2,678 & 2,678 & 2,678 & 2,678 & 2,678 \\
\hline Adusted. $-R^{2}$ & 0.018 & 0.022 & 0.023 & 0.029 & 0.064 & 0.028 & 0.024 \\
\hline
\end{tabular}


Panel E. Regressions conditional on at least one peripheral having a tail realization, using balance sheet exposure and restricting the sample to eurozone banks.

\begin{tabular}{|c|c|c|c|c|c|c|c|}
\hline & 1 & 2 & 3 & 4 & 5 & 6 & 7 \\
\hline Constant for positive tail days & $-0.480^{* * * 4}$ & $-0.257^{\text {** }}$ & $-0.413^{* * *}$ & $-0.209^{*}$ & $-0.207^{*}$ & $-0.521^{*}$ & -0.190 \\
\hline \multirow[t]{2}{*}{ Constant for negative tail days } & $0.733^{* * * *}$ & $0.434^{* *}$ & $0.652^{* * * *}$ & $0.516^{* * *}$ & $0.554^{* * *}$ & 0.562 & $0.598^{*}$ \\
\hline & $(0.055)$ & $(0.499)$ & $(0.063)$ & $(0.171)$ & $(0.138)$ & $(0.908)$ & $(0.191)$ \\
\hline Tail peripheral CDS return on positive tail days & & $-0.018^{* * *}$ & & $-0.017^{* * *}$ & $-0.017^{* * *}$ & & \\
\hline \multirow[t]{2}{*}{ Tail peripheral CDS return on negative tail days } & & -0.029 & & -0.013 & -0.010 & & \\
\hline & & $(0.606)$ & & $(0.862)$ & $(0.703)$ & & \\
\hline Exposure on positive tail days & & & $-25.622^{* *}$ & $-24.793^{* *}$ & $-24.498^{* *}$ & $-36.324^{* * *}$ & $-27.959^{* * *}$ \\
\hline \multirow[t]{2}{*}{ Exposure on negative tail days } & & & $38.630^{* * *}$ & $37.507^{* * *}$ & $28.602^{* *}$ & $40.354^{* *}$ & $38.764^{* *}$ \\
\hline & & & $(0.032)$ & $(0.034)$ & $(0.474)$ & $(0.784)$ & $(0.214)$ \\
\hline Exposure $\times$ Tail peripheral CDS return on positive tail days & & & & & -24.809 & & \\
\hline \multirow[t]{2}{*}{ Exposure $\times$ Tail peripheral CDS return on negative tail days } & & & & & $-260.731^{* * *}$ & & \\
\hline & & & & & $(0.003)$ & & \\
\hline Equity on positive tail days & & & & & & 3.224 & \\
\hline \multirow[t]{2}{*}{ Equity on negative tail days } & & & & & & 1.831 & \\
\hline & & & & & & $(0.482)$ & \\
\hline Equity $\times$ Exposure on positive tail days & & & & & & $1162.543^{* * *}$ & \\
\hline \multirow[t]{2}{*}{ Equity $\times$ Exposure on negative tail days } & & & & & & -217.797 & \\
\hline & & & & & & $(0.205)$ & \\
\hline Fragility on positive tail days & & & & & & & -0.772 \\
\hline \multirow[t]{2}{*}{ Fragility on negative tail days } & & & & & & & 0.189 \\
\hline & & & & & & & $(0.562)$ \\
\hline Fragility $\times$ Exposure on positive tail days & & & & & & & -65.215 \\
\hline \multirow[t]{2}{*}{ Fragility $\times$ Exposure on negative tail days } & & & & & & & 0.764 \\
\hline & & & & & & & $(0.552)$ \\
\hline Number of observations & 3,569 & 3,569 & 3,129 & 3,129 & 3,129 & 3,129 & 3,129 \\
\hline Adjusted- $R^{2}$ & 0.030 & 0.033 & 0.060 & 0.062 & 0.064 & 0.063 & 0.061 \\
\hline
\end{tabular}

